\section{OPEN ACCESS}

Edited by:

Andreas Zanzoni,

INSERM U1090 Technologies

Avancées pour le Génome et la

Clinique, France

Reviewed by:

Fabrizio Ferrè,

University of Bologna, Italy

Andre Paul Gerber

University of Surrey, United Kingdom

*Correspondence:

César Paz-y-Miño

cesar.pazymino@ute.edu.ec

Specialty section:

This article was submitted to

Protein and RNA Networks,

a section of the journal

Frontiers in Molecular Biosciences

Received: 08 May 2019

Accepted: 23 July 2019

Published: 07 August 2019

Citation:

García-Cárdenas JM, Guerrero S, López-Cortés A, Armendáriz-Castillo I,

Guevara-Ramírez P, Pérez-Villa A

Yumiceba V, Zambrano AK, Leone PE and Paz-y-Miño C (2019)

Post-transcriptional Regulation of

Colorectal Cancer: A Focus on

RNA-Binding Proteins.

Front. Mol. Biosci. 6:65

doi: $10.3389 /$ fmolb.2019.00065

\title{
Post-transcriptional Regulation of Colorectal Cancer: A Focus on RNA-Binding Proteins
}

\begin{abstract}
Jennyfer M. García-Cárdenas, Santiago Guerrero, Andrés López-Cortés, Isaac Armendáriz-Castillo, Patricia Guevara-Ramírez, Andy Pérez-Villa, Verónica Yumiceba, Ana Karina Zambrano, Paola E. Leone and César Paz-y-Miño*
\end{abstract}

Facultad de Ciencias de la Salud Eugenio Espejo, Centro de Investigación Genética y Genómica, Universidad UTE, Quito, Ecuador

Colorectal cancer $(\mathrm{CRC})$ is a major health problem with an estimated 1.8 million new cases worldwide. To date, most CRC studies have focused on DNA-related aberrations, leaving post-transcriptional processes under-studied. However, post-transcriptional alterations have been shown to play a significant part in the maintenance of cancer features. RNA binding proteins (RBPs) are uprising as critical regulators of every cancer hallmark, yet little is known regarding the underlying mechanisms and key downstream oncogenic targets. Currently, more than a thousand RBPs have been discovered in humans and only a few have been implicated in the carcinogenic process and even much less in CRC. Identification of cancer-related RBPs is of great interest to better understand CRC biology and potentially unveil new targets for cancer therapy and prognostic biomarkers. In this work, we reviewed all RBPs which have a role in CRC, including their control by microRNAs, xenograft studies and their clinical implications.

Keywords: colorectal cancer, RBPs, post-transcriptional regulation, oncogene, tumor suppressor

\section{INTRODUCTION}

Worldwide, every year an estimated 1.8 million new cases of colorectal cancer (CRC) are diagnosed, setting it in the third place of the most common malignant tumor, and consequently a major health care problem (Gao et al., 2015; Bray et al., 2018). Heretofore, most studies in CRC biology have been focused on DNA-related aberrations (e.g., mutation, methylation changes, DNA copy number alterations, loss of genomic stability, etc.), leaving the post-transcriptional processes under-studied. However, post-transcriptional alterations play a significant role in the preservation of tumor cells by modulating every hallmark in cancer (Lukong et al., 2008; Morris et al., 2012; Paz-Y-Mino et al., 2015; Wurth et al., 2016; Martinez-Useros et al., 2017).

RNA biology represents an under-investigated aspect of cancer; this is puzzling considering that pleiotropic changes in the transcriptome are a key feature of cancer cells (Wurth and Gebauer, 2015). RNA binding proteins (RBPs) are relevant because they are part of post-transcriptional RNA regulons. These RNA regulons are formed by Ribonucleoproteins (RNP) which interact with other trans-elements, non-coding RNAs, metabolites and untranslated sequence elements found within the mRNAs (USER). These RNP complexes control the expression of hundreds to thousands mRNAs of functionally related proteins from the transcription to translation process, allowing the cell to respond to several stimuli with such a great agility ensuring cellular homeostasis (Keene, 2007; Wurth, 2012; Iadevaia and Gerber, 2015; Wurth and Gebauer, 2015). The complex interaction 
of RBPs and their RNA partners (e.g., mRNAs or miRNAs) are achieved through RNA-recognition domains which increases the specificity and affinity of these interactions. While there is much progress still to understand such interactions, some of these domains have been ully characterized: the RNArecognition motif (RRM), the zinc finger motif, and the Khomology domain (Iadevaia and Gerber, 2015). RBPs are able to control every aspect of RNA metabolism: capping, splicing, polyadenylation, nucleocytoplasmic transport, stability, translation, and degradation of mRNA (Burd and Dreyfuss, 1994; Lukong et al., 2008; Kechavarzi and Janga, 2014). As a result, when any RBP is altered this affect either its mRNA affinity or its subcellular localization, disturbing cellular homeostasis (Iadevaia and Gerber, 2015). In this regard, RBPs are emerging as critical modulators of every hallmark of cancer, and still very little is known about their cancer related molecular functions and targets (Wurth and Gebauer, 2015; Hentze et al., 2018).

Hentze et al. compiled all published RNA interactomes into RBP supersets, they stringently curated and updated the annotations of RBPs identified from several sources. Finally, a list of 1,393 RBPs was retrieved in humans and only a few have been implicated in the carcinogenic process and even much less in CRC (Hentze et al., 2018). The identification of RBPs will provide a better understanding of tumor biology and potentially unveil new targets for cancer therapy and prognostic biomarkers. In this work, we reviewed all RBPs having a role in CRC, including their control by microRNAs (miRNAs), xenograft studies and their clinical implications.

\section{LIN28}

\section{General Features}

LIN28 is an evolutionarily conserved RBP and an emerging oncogenic driver (Zhang et al., 2018). Mammals produce two LIN28 paralogs, LIN28A and LIN28B which are separately or jointly involved in various biological functions; including metabolism development, tissue regeneration, and oncogenesis ( Tu et al., 2015; Wang T. et al., 2015; Jiang and Baltimore, 2016; Wang et al., 2016; Pereira et al., 2017). Human Lin28A is located on chromosome 1p36 and encodes a protein of 209 amino acids whereas $\operatorname{Lin} 28 B$ is on chromosome $6 \mathrm{q} 16.3$ and its protein is composed of 250 amino acids. In addition, LIN28A is predominantly localized in the cytoplasm, whereas LIN28B resides exclusively in the nucleus. Interestingly, both proteins are expressed mainly in the cytoplasm in CRC (Guo et al., 2006; Wang et al., 2016).

LIN28 proteins have two cold shock domains and retroviraltype Cys-Cys-His-Cys (CCHC) zinc fingers that confer RNAbinding ability. These proteins also modulate the let- 7 family of miRNAs, which consists of 12 members frequently deleted in human cancers and considered as tumor suppressors (Zhou et al., 2013; Triboulet et al., 2015; Wang S. et al., 2015; Jiang and Baltimore, 2016; Jiang et al., 2017). Both proteins inhibit biogenesis and induce the degradation of the let-7 family. LIN28B interacts with pri-let-7 (primary-miRNAs) and inhibits its processing by the Microprocessor complex, whereas LIN28A blocks the pre-let-7 (the hairpin structure formed by the cleavage of DROSHA/DGCR8 enzymes) processing by DICER1 via TUT4 recruitment (Kim et al., 2014; Wang et al., 2016). Conversely, there is a double-negative feedback loop, where the $3^{\prime}$ UTR of LIN28A/B is recognized by let-7 miRNA. Thus, once let-7 miRNA binds to the $3^{\prime}$ UTR the expression of these proteins is inhibited (Wang T. et al., 2015). Indicating that when LIN28A/B are expressed let-7 is not (Piskounova et al., 2011; Wang T. et al., 2015).

Both LIN28A and LIN28B could enhance colon cancer cells proliferation but mechanically their mode of action is different. LIN28A overexpression promotes the transition from $S$ to G2/M phase, whereas constitutive expression of LIN28B enables the shift of cell cycle phases (from G1 to $S$ phase and from $S$ to G2/M phase) (Wang et al., 2016). Activation of LIN28 in different primary tumors leads to translational enhancement or suppression of cancer-related mRNAs (e.g., IGF2 and MYOD1 mRNAs) (Viswanathan and Daley, 2010; Rappaport et al., 2017). Both LIN28A and LIN28B are expressed in about 30\% of colorectal tumors, but the expression level of $L I N 28 B$ is higher compared to LIN28A (King et al., 2011a,b; Wang et al., 2016).

\section{Xenograft Studies}

LIN28B knockdown in cancer cells reduces their proliferative and invasive abilities in vitro and inhibits both primary and metastatic tumor growth in vivo (Jiang et al., 2017). LIN28B increases cancer cell invasion in intestinal and colorectal adenocarcinomas in murine models (Jiang et al., 2017). Also, LIN28 overexpressed tumors exhibited augmented areas of moderate differentiation and increased glandular formation and mucin production; in contrast to wild-type tumors that are poorly differentiated and rarely exhibit mucinous (King et al., 2011a). In addition, Tu et al. experimentally demonstrated that LIN28 cooperates with APC in accelerating neoplastic lesions formation in $A p c^{\mathrm{Min} /+}$ mice. APC alterations (or other changes that target WNT signaling) occur in most colon tumors, which could be upregulating the expression of LIN28B. This may be mediated by MYC, a transcriptional target of the canonical WNT signaling (Mayr et al., 2007; King et al., 2011a; Zhou et al., 2013; Wang et al., 2016; Pereira et al., 2017). It has also been demonstrated that LIN28/let-7 axis promotes invasive intestinal adenocarcinoma in murine models by interacting with the WNT pathway (Piskounova et al., 2008; Tu et al., 2015; Voutsadakis, 2018).

\section{miRNAs Control}

To date, besides let-7, several miRNAs have been reported to repress LIN28A/LIN28B translation once they bind to their 3'UTR, such as miR-9, miR-26a, miR-27, miR-30, miR-125, miR-181, and miR-212. In cancer cells, these miRNAs are under-expressed due to $L I N 28 A / B$ overexpression (Wang T. et al., 2015).

\section{Clinical Relevance}

LIN28A/LIN28B influence the clinical outcome in patients by enhancing tumor aggressiveness and early metastasis (Mayr et al., 2007; Viswanathan et al., 2009; King et al., 2011a; Wang et al., 2016; Pereira et al., 2017). Irregular LIN28A/B expression is usually correlated with poor survival. Several studies have 
demonstrated that high levels of LIN28 in colon tumors are associated with advanced tumor stages and increased probability of tumor recurrence (King et al., 2011a; Madison et al., 2013; Jiang and Baltimore, 2016; Zhang et al., 2018). King et al. have found that LIN28B protein levels are increased in CRC patients promoting cancer progression and metastasis (King et al., 2011a). In addition, over-expression of LIN28A/LIN28B could enhance chemotherapy sensitivity of HCT116 cells to 5 -Fu via different mechanisms (Wang et al., 2016). LIN28 may also serve as a predictive biomarker for chemotherapy in patients with colon cancer (King et al., 2011a; Pang et al., 2014; Wang T. et al., 2015; Wang et al., 2016; Jiang et al., 2017). All RBPs and their CRC-related features are listed in Table 1.

\section{MSI}

\section{General Features}

In humans, Musashi RNA binding protein (MSI) is composed of two isoforms: MSI1 and MSI2 (Voutsadakis, 2018). MSI1 and MSI2 genes are evolutionarily conserved given their 75\% amino acid sequence. These two proteins are placed on chromosome 12q24 (MSI1) and 17q22 (MSI2). They comprise two RNA recognition motif (RRMs) domains which bind to (G/A)U13(AGU) motifs in the $3^{\prime}$-UTR of their target mRNAs (Sakakibara et al., 2001; Okano et al., 2005; Glazer et al., 2012). They can be regulated by ELAV1 by maintaining the stabilization of their mRNAs, as well as by tumor suppressor miRNAs (Gao et al., 2015). Musashi emerges as a critical player in controlling multiple targets that form networks from where MSI1 and MSI2 are able to regulate cell death, differentiation, and cell cycle (de Sousa Abreu et al., 2009; Guinney et al., 2015; Kharas and Lengner, 2017). They are also key oncogenic players in promoting intestinal transformation (Wang S. et al., 2015; Kharas and Lengner, 2017). Musashi may also co-operate with LIN28 by binding and inhibiting some mRNAs. Besides, Musashi represses translation of Numb (an inhibitor of the NOTCH pathway), APC, PTEN, and P21, but upregulates WNT pathway at transcriptional level when Numb is inhibited (Qiao and Wong, 2009; Lan et al., 2015; Wang S. et al., 2015; Voutsadakis, 2018).

\section{Xenograft Studies}

Several studies have shown the potential therapeutic target of MSI1 given that when MSI1 is knockdown tumor growth is delayed as well as cell proliferation, migration, and invasion (Sureban et al., 2008; Gao et al., 2015; Smith, 2015; Kharas and Lengner, 2017). In addition, murine models upregulated for MSI1 and K-RasG12D are highly resistant to oxaliplatin and 5-fluorouracil (Todaro et al., 2014).

\section{miRNA Control}

miR-137 is a tumor suppressor, which negatively regulates MSI1 and Notch/WNT signaling pathway (Smith, 2015). There is an inverse correlation between miR-137 and MSI1 expression; thus, the overexpression of miR-137 decreases MSl1 expression reducing cell growth, colony formation, and tumor sphere growth (Liang et al., 2013; Smith et al., 2015).

\section{Clinical Relevance}

MSI1/2 are highly expressed in colon primary tumors and metastatic lesions in the lymph nodes; this correlates to an increased metastatic risk and poorer survival (Fan et al., 2010; Li et al., 2011). Therefore, it has been suggested that inhibition of both MSIs' RNA binding activity could fully abrogate tumor growth in CRC (Potten et al., 2003; Cheng et al., 2015; Gao et al., 2015; Lan et al., 2015; Kharas and Lengner, 2017). Besides, MSI increases colorectal cancer stem cells (CSCs) survival, migration, and resistance to 5-FU, the chemotherapy drug that constitutes the backbone of the most currently used one in colon cancer treatment (Yuqi et al., 2008; Voutsadakis, 2018; López-Cortés et al., 2019).

\section{ELAVL1}

\section{General Features}

Embryonic Lethal, Abnormal Vision Drosophila-Like 1 (ELAVL1) or $\mathrm{Hu}$ Antigen $\mathrm{R}(H u R)$ was the first factor to be identified for its ability to cooperate and compete with miRNA activity (Franceschini et al., 2012; Ciafrè and Galardi, 2013; Iadevaia and Gerber, 2015). ELAVL1 consists of 326 amino acids harboring three RRMs, which bind to specific mRNAs in their AU- or U-rich elements (AREs) in their 3'UTRs (López de Silanes et al., 2004b). ELAVL1 expression changes were found to occur early during tumorigenesis (Fan and Steitz, 1998), upregulating key survival or growth-related genes by increasing both their mRNA stability and/or their protein translation (Fan and Steitz, 1998; López de Silanes et al., 2004b; Franceschini et al., 2012). For example, ELAVL1 promotes the stability and translation of COX-2 mRNA by binding to its ARE sequences located within the $3^{\prime}$ UTR in an advanced tumor stage of CRC tissues (Fan and Steitz, 1998; Dixon et al., 2001; Denkert et al., 2006; Badawi et al., 2017). COX-2 is a major facilitator of several cellular activities (e.g., proliferation, cell death resistance, angiogenesis, and metastasis) (Fan and Steitz, 1998; Denkert et al., 2006; Jang et al., 2017; López-Cortés et al., 2019). ELAVL1 is normally found in the nucleus, where it participates in splicing and polyadenylation, but in CRC cells ELAVL1 is localized in the cytoplasm promoting mRNA stabilization of its targets (Fan and Steitz, 1998; Brennan and Steitz, 2001; López de Silanes et al., 2011; Akaike et al., 2014; Liu et al., 2018). ELAVL1 regulates numerous mRNAs that encode proteins related to proliferation, cell cycle (cyclins A2, B1, D1, p21, and p27), tumor suppressors (p53 and Von Hippel-Lindau tumor suppressor), proto-oncogene products (c-Fos and c-Myc), growth factors (IGF-1R VEGF, EGF, TGF, GM-CSF), inhibitors (p21 and p27) and signaling molecules, which are crucial ( $\beta$-catenin, cyclin D1, and c-Myc) for the CRC WNT-activated pathway (Lin et al., 2017).

\section{Xenograft Studies}

ELAVL1 enhances pathogenic gene expression necessary for cancer development (Blanco et al., 2016). This was corroborated when ELAVL1 overexpression increased colon cancer cells growth in a nude mouse xenograft model (López de Silanes et al., 2004b; Liu et al., 2018). Subcutaneous injection of ELAVL1-overexpressing RKO cells into nude mice produced 
TABLE 1 | A summary of all CRC-related RBPs reviewed in this work: miRNAs control and their clinical relevance.

\begin{tabular}{|c|c|c|}
\hline RBP & Control by miRNAs & Clinical relevance \\
\hline LIN28 & $\begin{array}{l}\text { miR-let-7, miR-26a, miR-181, } \\
\text { miR-9, miR-30, miR-125, } \\
\text { miR-212 and miR-27 }\end{array}$ & $\begin{array}{l}\text { - Aberrant expression correlates with reduced patient survival. } \\
\text { - Predictive biomarker for chemotherapy. }\end{array}$ \\
\hline MSI & miR-137 & $\begin{array}{l}\text { - High expression correlates with increased metastatic risk and poorer survival. } \\
\text { - Promotes resistance to 5-FU. }\end{array}$ \\
\hline ELAVL1 & miR-519 and miR-22 & - High expression correlates with malignancy and multidrug resistance. \\
\hline RBM3 & & - Promotes resistance to chemotherapy \\
\hline CELF1 & miR-503 & \\
\hline IGF2BPs & & $\begin{array}{l}\text { - Overexpression correlates to unfavorable clinical outcomes: early dissemination, } \\
\text { poor response to the therapy, increased tumor aggressiveness, and short survival. }\end{array}$ \\
\hline ESRP1 & & - Overexpression associates with a favorable overall survival outcome. \\
\hline TIA1 & miR-19a & $\begin{array}{l}\text { - Increased numbers of TIA-1 positive TILs is associated with an improved clinical } \\
\text { outcome. } \\
\text { - TIA1 can also be used to supplement prognostic information related to TNM stage } \\
\text { and adjuvant therapy. }\end{array}$ \\
\hline KHDRBS1 & & $\begin{array}{l}\text { - KHDRBS1 nuclear localization and overexpression is correlated with poor tumor } \\
\text { differentiation, advanced T stage, lymph node involvement, and distant metastasis. }\end{array}$ \\
\hline CPEB4 & miR-203 & - Overexpression correlates with tumor progression and poor overall survival. \\
\hline CSDE1 & & - Overexpression is associated to poor prognosis. \\
\hline
\end{tabular}

significantly larger tumors; conversely, RKO cells expressing low ELAVL1 levels significantly reduced tumor growth (López de Silanes et al., 2003). ELAVL1 deletion in adult normal mice was lethal and several critical defects were observed: defective intestinal stem cell dynamics, villus atrophy, and defects in hematopoietic progenitor cell production (Ghosh et al., 2009). Mice lacking ELAVL1 in myeloid-lineage cells, which include many of the innate immune system cells, showed a rapid progression of chemical-induced colitis and increased susceptibility to endotoxemia and colitis-associated cancer (Yiakouvaki et al., 2012).

\section{miRNAs Control}

ELAVL1 levels are downregulated by miR-519, a tumorsuppressive miRNA. miR-519 promotes anti-proliferative properties in CRC cell lines by targeting and reducing ELAVL1 transcripts. This, in turn, decreases the expression of several ELAVL1 target mRNAs and markedly reduces cell proliferation (Abdelmohsen et al., 2008). ELAVL1 levels are also downregulated by miR-22, which has a more profound tumorsuppressive effect. Expression of miR-22 is inversely correlated with ELAVL1 in both CRC tissues and CRC cell lines. miR-22 directly binds to the $3^{\prime}$ UTR of ELAVL1 leading to its inhibition, which, in turn, represses CRC proliferation and migration in vitro and decelerates CRC xenografted tumor growth in vivo (5). Conversely, Al-Haidari et al. have found that when miR-155-5p expression was reduced in serum-starved CRC cells, it decreased the expression of ELAVL1 (Al-Haidari et al., 2018).

\section{Clinical Relevance}

Increased expression and cytoplasmic abundance of ELAVL1 is correlated with malignancy in colon cancer tissues (López de Silanes et al., 2004a; Denkert et al., 2006). Numerous studies have indicated that cytoplasmic accumulation of ELAVL1 has a link to multidrug resistance (MDR) acquired after chemotherapy and therefore causing poor prognosis in various cancer types. Accordingly, suppression of ELAVL1's cytoplasmic accumulation could increase chemotherapeutic agent accumulation and induced apoptosis, leading to increased cytotoxic effect and reversing drug resistance (Blanco et al., 2016; Lin et al., 2017). ELAVL1 inhibition could, therefore, improve the efficacy of current therapy regimes (Badawi et al., 2017; Lin et al., 2017).

\section{QKI}

\section{General Features}

Quaking (QKI) is a human RBP placed on chromosome 6q26. QKI is part of STAR (signal transduction and activation of RNA) protein family and presents two specific regions (QUA1 and QUA2) and a $\mathrm{KH}$ domain. So far, four mRNA splice variants have been recognized: QKI-5, QKI-6, QKI-7, and QKI7b (Kondo et al., 1999; Yang et al., 2010). The 3 well-studied isoforms (QKI5, 6, and 7) appear to have different roles in development. QKI isoforms are constructed with the same 311 amino acid body (share exons 1-6), however, their Cterminal differs from the rest (35 amino acids) (Yang et al., 2010). From all human isoforms, QKI-5 is the most abundant in colon tissues where its maximum expression is seen in the 
nucleus, while QKI-7 is mainly a cytoplasmic protein. QKI-6 can be found in both nuclear and cytoplasmic compartments (Yang et al., 2010; Ji et al., 2013). The cellular localization of QKI7b remains unknown due to the lack of specific antibodies (Liu Q. et al., 2013).

QKI affects several RNA-related processes (pre-mRNA splicing, mRNA stabilization and turnover, nuclear retention, miRNA processing, and circular RNA biogenesis), regulating cell cycle and differentiation, programmed cell death, development, new blood vessels formation, and cell fate determination (Nilsen and Graveley, 2010; Ji et al., 2013). To date, altered expression of the STAR proteins has been seen in several developmental defects and diseases. Concerning to CRC, Yang et al. discovered that QKI5 and QKI6 are very little expressed or even absent, acting as tumor suppressor proteins. This was associated with unusual regulation of $\beta$-catenin and p27Kip1 signaling (Yang et al., 2010). This reduction in QKI expression has been for an anomalous dropping of the histone variant macroH2A1.1 (Ji et al., 2013). QKI is a critical regulator of colon epithelial differentiation, whose aberrant reduction (hypermethylation) might contribute to gastrointestinal cancer initiation and facilitate colon carcinogenesis (Yang et al., 2010; Iwata et al., 2017).

\section{Xenograft Studies}

QKI null mice phenotype presented several abnormalities in the vascular remodeling or vitelline vessels that make them impossible to survive later of the day 10.5. QKI conditional knockout mice died by the third week after birth, displaying severe hypomyelination in the central nervous system (Darbelli et al., 2016). The lethal phenotype in QKI knockout mice highlights the importance of this gene in the regulation of normal cellular functions (Yang et al., 2010).

\section{miRNAs Control}

miR-574-5p negatively controls the expression of QKI6/7/7b through binding to QKI's 3'UTRs. This negatively regulation has been seen in mice and humans colorectal tissues where $\beta$-catenin and $\mathrm{p} 27 \mathrm{Kip} 1$ signaling is affected once miR-574-5p is significant upregulated (Ji et al., 2013). Another regulator is miR-155 which downregulates $Q K I$ and thus promotes proliferation and invasion of CRC cells (He et al., 2015).

\section{Clinical Relevance}

Low QKI expression is a risk factor for tumor recurrence after surgery. Thus, patients with low QKI expression had significantly poorer prognosis. Furthermore, the relapse-free survival (RFS) and overall survival of patients with stage I, II, and III CRC with low QKI expression was significantly shorter than those with high QKI expression. QKI could be therefore a useful clinical biomarker for predicting recurrence and prognosis (Iwata et al., 2017). In addition, if methylationrelated mechanisms contribute to the inactivation of QKI, demethylation could be an appropriate therapeutic strategy (Yang et al., 2010; Iwata et al., 2017).

\section{RBM3}

\section{General Features}

RNA-binding motif protein 3 (RBM3) has been identified as a cold-shock protein. RBM is activated in cellular distress (e.g., hypothermia, hypoxia, and oxidative stress), but it is necessary for cell proliferation (Melling et al., 2016; Siesing et al., 2017). RBM3 is part of the glycine-rich RNA-binding protein family and has one RRM domain. Currently, two isoforms have been identified where the longest comprehends 157 amino acids with a molecular mass of $17 \mathrm{kD}$ (Derry et al., 1995; Melling et al., 2016; Jang et al., 2017; Rappaport et al., 2017). Cold-shock proteins have been suggested to be important mediators of the caspase-independent mitotic death (CIMD) (Jang et al., 2017). RBM3 interferes the access of mRNA initiation factors to the $60 \mathrm{~S}$ ribosome which modulates the potential activity of kinases in tumors (Chappell and Mauro, 2003; Dresios et al., 2005).

RBM3 plays a key role in carcinogenesis and proto-oncogene function. RBM3 augments mRNA stability and translation of rapidly degraded transcripts by binding to their AREs; for instance, RBM3 stabilizes COX-2, IL-8, and VEGF (Sureban et al., 2008; Venugopal et al., 2016). These cells also exhibit augmented stem cell markers via an increase in $\beta$-catenin activity. Therefore, the $\beta$-catenin signaling pathway may be regulated through alterations in the expression of $R B M 3$. Interestingly, RBM3 is also regulated by hypoxia in a HIF1 $\alpha$ independent mechanism; this provides a novel target to further examine RBM3-mediated hypoxia induced stem cell signaling (Venugopal et al., 2016).

\section{Xenograft Studies}

$R B M 3$ overexpression enhanced the development of multicellular tumor spheroids in NIH3T3 mouse fibroblasts. This suggests that $R B M 3$ could malignantly transform cells by inducing anchorageindependent growth. However, in xenografts models RBM3 downregulation reduces tumor growth and angiogenesis. Given the reduction in the expression of $I L-8$ and the proangiogenic factors COX-2 and VEGF (Sureban et al., 2008).

\section{miRNAs Control}

It has been reported that RBM3 alters miRNA levels which in turn will modify global protein expression and thus tumor progression (Jang et al., 2017).

\section{Clinical Relevance}

RBM3 overexpression in HCT116 and DLD1 colon cancer cells increases proliferation and engenders hypoxia, serum deprivation and resistance to classical chemotherapeutic agents (e.g., cisplatin, doxorubicin, and paclitaxel) (Venugopal et al., 2016). It has been suggested that RBM3 is capable of increasing chemoresistance by inducing cells with high xenobiotic efflux capacity and through the induction of ATPbinding cassette (ABC) transporters (Venugopal et al., 2016). In contrast, RBM3 downregulation decreases HCT116 colon adenocarcinoma cell proliferation (Sureban et al., 2008). There is an association between RBM3 and more favorable clinic 
pathological parameters, the higher $R B M 3$ expression, the higher the disease-free survival (DFS) rate is, particularly in patients who received first line oxaliplatin-based chemotherapy (Jones et al., 2014; Venugopal et al., 2016; Jang et al., 2017; Liu Y. et al., 2017; Siesing et al., 2017; Ye et al., 2017).

Besides, a positive relationship between microsatellite instability with high expression of $R B M 3$ was observed (Venugopal et al., 2016; Jang et al., 2017). High microsatellite instability is commonly associated with good prognosis and right-sided colon cancer development. Melling and colleagues found that the higher the expression of $R B M 3$ the higher the overall survival is in CRC (stages I-III). This may be clinically relevant for the selection of patients with a likely adverse clinical course for adjuvant chemotherapy. Although, no difference in survival was seen for rectal carcinomas (Melling et al., 2016). Noteworthy, Wang and colleagues found that RBM3 positive expression correlates with an improved prognosis in young CRC patients (Wang M. J. et al., 2015).

\section{CELF1}

\section{General Features}

CUGBP Elav-like family member 1 (CELF1), is a multifunctional RBP that generally binds mRNAs through GU-rich elements in the $3^{\prime}$-UTRs or coding regions of its targets. CELF1 forms part of a family named CELF (CELF1, CELF2, CELF3, CELF4, CELF5, and CELF6). All the family members possess a divergent domain loaded with alanine and glutamine residues and three RRMs, two near the N-terminal region and one located at the C-terminal domain. CELF1 promotes and represses RNA splicing and mRNA translation (Kim and Gorospe, 2008; Vlasova et al., 2008; Vlasova-St. Louis and Bohjanen, 2011; Yang et al., 2014; Liu et al., 2015). The three of them recognize different motifs and arrangements, which gives specificity and a wide range of binding partners. CELF1 regulates protein expression implicated in the tight junction (TJ) and gut barrier function. For instance, CELF1 represses occludin translation by increasing occludin mRNA recruitment to processing bodies, resulting in dysfunction of the epithelial barrier. Interestingly, CELF1 and ELAVL1 compete for the same occludin $3^{\prime}$ UTR binding element, competitively regulating occludin translation and in opposite directions (Yang et al., 2014; Liu et al., 2015). CELF1 also regulates intestinal epithelial homeostasis by modulating intestinal epithelial cells (IECs) proliferation, apoptosis and cellto-cell interaction (Cui et al., 2012; Liu et al., 2015). Increased levels of cellular CELF1 desensitize IECs to apoptosis, whereas CELF1 silencing increases the sensitivity of IECs to apoptosis (Cui et al., 2012; Tu et al., 2015).

\section{Xenograft Studies}

In a mouse fasting model, a reduction in the proliferating crypt cell population and a decrease in the lengths of villi and crypts were correlated with a significant increase in the levels of CELF1. This suggests the involvement of CELF1 in the pathogenesis of intestinal mucosal atrophy (Madison et al., 2013, 2015; Liu et al., 2015).

\section{miRNA Control}

CELF1 is repressed by the tumor suppressor miR-503 in IECs. CELF1 abundance is regulated by miRNA-503 mostly by binding to sites located in CELF1 coding region (Ciafrè and Galardi, 2013; Yang et al., 2014; Liu et al., 2015).

\section{CELF2}

\section{General Features}

CUGBP Elav-like family member 2 (CELF2) is a ubiquitously expressed protein of 490 amino acids located on chromosome 10p13-p14 (Choi et al., 1999; Lichtner et al., 2002; Ramalingam et al., 2012). CELF2 regulates several RNAs at different posttranscriptional levels: alternative splicing (e.g., Tau and troponin T), RNA editing (e.g., apolipoprotein B), RNA stability, and mRNA translation (e.g., cyclooxygenase-2 and Mcl1) (Ramalingam et al., 2012). CELF2 is expressed in the nucleus of intestinal epithelial cells acting as a tumor suppressor protein (Natarajan et al., 2008). CELF2 has at least three identified isoforms, each of them with differential expression levels in human colon cancer cells (Ramalingam et al., 2008). CELF2 overexpression results in reduced colony formation in CRC cells. CELF2 attaches to AREs of COX-2 3'UTR increasing COX-2 mRNA stability but inhibiting its translation. Reduction of COX-2, in turn, decreases PGE2 known to modulate cell proliferation and tumor invasion in many cancer types (Sureban et al., 2008; Ramalingam et al., 2012). COX-2 is upregulated in colorectal adenomas, thereby suggesting that CELF2 might prevent cancer development by inhibiting COX-2 and PGE2. These data suggest that CELF2 expression may be deleterious to cancer cells (Ramalingam et al., 2012).

\section{IGF2BP1-3}

\section{General Features}

The mammalian IGF2 mRNA-binding protein family (IGF2BP) comprises three RNA-binding proteins (IGF2BP1-3) with a conserved domain structure including four K homology $(\mathrm{KH})$ domains and two RRMs (Ross et al., 2001; Dimitriadis et al., 2007; Lederer et al., 2014). IGF2BPs exhibit different expression patterns despite their high degree of likeness and show distinct RNA-binding properties and are associated with variable target transcripts. IGF2BP1 stabilizes the MYC mRNA by shielding it from ribonuclease cleavage when binding to the coding region instability determinant (Lederer et al., 2014). Thereby, it prolongs the half-life of MYC mRNA up to 8 fold, promoting tumor cell proliferation and survival (Ross et al., 2001; Dimitriadis et al., 2007; Hamilton et al., 2013; Lederer et al., 2014). IGF2BP1 also regulates CD44, ALCAM, AMIGO2, MCAM, CD24, dysadherin, and MMP1 mRNAs that encode proteins of cell adhesion and invasiveness (Dimitriadis et al., 2007; Vainer et al., 2008). In addition, IGF2BP1 binds to and stabilizes F-box protein $\beta \operatorname{TrCP} 1$ whose continued activation in CRC is well established by suppressing apoptosis via NF- $\kappa$ B activation (Dimitriadis et al., 2007; Hamilton et al., 2013).

Concerning IGF2BP2, it has been shown that this RBP controls NRAS, PINCH2, and MURF-3 expression which are 
responsible for carcinogenesis and cellular mobility (Lederer et al., 2014; Ye et al., 2016). In addition, IGF2BP2 targets RAF1 mRNA which is an essential component of MAPK pathway activation upon (MEK)1/2 phosphorylation. MEK1/2, in turn, phosphorylate and activate extracellular-related kinase (ERK)1/2. ERK1/2 regulate downstream pathways involved in survival and cell proliferation (Ye et al., 2016).

Regarding IGF2BP3, this protein contributes to RNA trafficking and stabilization, cell development and division, migration and adhesion (Lochhead et al., 2012; Lin et al., 2013; Lederer et al., 2014; Kumara et al., 2015). Also, in vitro studies have shown that IGF2BP3 promotes tumor cell survival, proliferation, anchorage-independent growth, chemoresistance migration and invasiveness (Lederer et al., 2014). It has been demonstrated that IGF2BP3 along with HNRNPM controls the fate of cyclin D1, D3, and G1 encoding transcripts in the nucleus (Li et al., 2009; Lederer et al., 2014). Cyclins are key components of the cell cycle and disorders of their function can lead to carcinogenesis. IGF2BP3 also regulates the gene expression of IGF-II, which binds to and activates IGF-I. Thus, IGF-I induces a cell to begin cell division in an alter manner which in turn causes excessive cell proliferation and cancer (Lin et al., 2013).

\section{Xenograft Studies}

IGF2BP1 plays an essential role for normal intestinal morphogenesis since deficient mice exhibit dwarfism and severe histological abnormalities in small (villous hypoplasia) and large intestine (short and irregular crypts in the colon) (Dimitriadis et al., 2007). On the contrary, IGF2BP1 overexpression promotes tumor-cell growth in CRC (Hamilton et al., 2013). IGF2BP2 knock-out mice possess a higher frequency of autoantibody response to IGF2BP2/p62 in colon cancer, although the mechanisms and its role in CRC carcinogenesis are still unknown (Ye et al., 2016). Ectopic expression of IGF2BP3 enhances tumor cell aggressiveness in transgenic animals (Dimitriadis et al., 2007; Lederer et al., 2014).

\section{miRNAs Control}

No miRNA has been reported to inhibit any member of the IGF2BP family. However, these RBPs protect some mRNAs from miRNA attack. For instance, IGF2BP1 protects Beta-transducin repeats-containing protein $1(\beta \operatorname{TrCP} 1)$ mRNA, an important player in signal transduction, from miR-183-directed turnover (Elcheva et al., 2009; Ciafrè and Galardi, 2013). Also, IGF2BP2 regulates RAF1 (proto-oncogene) expression by blocking its degradation by miR-195 (Ye et al., 2016).

\section{Clinical Relevance}

The suppression of apoptosis via NF- $\kappa \mathrm{B}$ activation originated by IGF2BP1 in tumors are linked to unfavorable clinical outcomes in CRC patients. These patients present propensity toward early dissemination, poor response to therapy and increased tumor aggressiveness. On the contrary, the absence of IGF2BP1 expression is an independent favorable prognostic factor for survival (Dimitriadis et al., 2007; Vainer et al., 2008; Hamilton et al., 2013). CRC patients also present a high antibody response to IGF2BP2, making this protein a possible biomarker for diagnosis and prognosis (Liu W. et al., 2013). Furthermore, IGF2BP2 may be important for chemoresistance and recurrence of the disease, given its participation in the maintenance of CSCs (Degrauwe et al., 2016; Jang et al., 2017). Concerning IGF2BP3 clinical relevance, it has been shown that this protein is a marker for aggressiveness, poor differentiation and tumor progression and it is related with an unfavorable prognostic and short survival times (Lochhead et al., 2012; Lederer et al., 2014; Chen et al., 2017). Also, IGF2BP3 positive patients have a nearly 11-fold increased risk of distant metastases (Li et al., 2009; Lin et al., 2013; Wei et al., 2015; Chen et al., 2017). This strong correlation suggests, that IGF2BP3 plays an important role in epithelialmesenchymal transition (EMT) (Li et al., 2009; Lin et al., 2013; Wei et al., 2015; Chen et al., 2017).

\section{ESRP1}

\section{General Features}

Also named RBM35A, epithelial splicing regulatory protein 1 (ESRP1) contains three putative RRMs, which are mutational hotspots of primary colon tumors with microsatellite instability (MSI) causing rapid degradation of the mutated transcripts (Leontieva and Ionov, 2009; Deloria et al., 2016; Mager et al., 2017). ESRP1 controls alternative splicing and regulates mRNA stability and translation of several mRNAs (Fagoonee et al., 2017). For example, ESRP1 has been identified as a key regulator for Ig-like III domain variant splicing of the fibroblast growth factor receptor 2 (FGFR2). Also, ESRP1 regulates transcript variants from genes associated with EMT such as CD44, ENAH, and CTNND1 (p120-catenin) (Deloria et al., 2016). ESRP1 is a tumor suppressor in CRC due to their ability to regulate translation of several cancer-related genes by binding to their mRNA 5'UTRs. In addition, ESRP1 suppresses cancer cell motility through distinct mechanisms during EMT (Leontieva and Ionov, 2009; Deloria et al., 2016; Fagoonee et al., 2017). Ectopic expression of ESRP1 protein resulted in suppression of tumorigenic potential of LS180 colon cancer cells (Leontieva and Ionov, 2009). ESRP1 is negatively regulated by mesenchymal transcription factors such as SNAIL, ZEB1, and ZEB2 (Mager et al., 2017).

Despite its role as a tumor suppressor, Fagoonee et al. recently demonstrated a pro-metastatic function of ESRP1 (Fagoonee et al., 2017). ESRP1 contributes to anchorageindependent growth of CRC cells, when Caco-2 cells are grown in suspension, enhances FGFR1/2 signaling, supports constant Akt phosphorylation and Snail upregulation. FGFR or PI3K/Akt inhibition reverted the pro-oncogenic phenotype of ESRP1 upregulation. High ESRP1 expression may stimulate cancer epithelial cell growth in the colon, as well as, at distant sites promoting CRC progression (Fagoonee et al., 2017).

\section{Xenografts Studies}

ESRP1 has a key role in intestinal homeostasis and disease in mice (Mager et al., 2017). Partial loss of ESRP1 function impairs intestinal epithelial barrier integrity, increases susceptibility to colitis and alters CRC development. In addition, ESRP1 overexpression has been correlated with liver macrometastasis in 
murine models, probably due to its ability to promote cancer cell growth at distant sites (Fagoonee et al., 2017).

\section{Clinical Relevance}

ESRP1 expression is associated with a favorable overall survival outcome in CRC patients. On the contrary, loss of ESRP1 expression negatively correlates with CRC patient survival (Mager et al., 2017). Decreased ESRP1 expression might also indicate the presence of EMT and thus disease progression and metastasis (Deloria et al., 2016). In addition, by upregulating Snail expression, ESRP1 has been associated with poor prognosis and shortened relapse-free survival (Fagoonee et al., 2017).

\section{TTP}

\section{General Features}

Tristetraprolin (TTP) also called ZFP36 or TIS11 forms part of a family of tandem Cys3His zinc finger proteins (Lai et al., 1999; Sharma et al., 2013; Sobolewski et al., 2015; Lee et al., 2018). TPP is mainly cytoplasmic, where interacts with stress granules (SGs), regulates mRNA stability and promotes degradation of inflammatory cytokines, proto-oncogenes and growth regulatory genes (Carrick and Blackshear, 2007; Cha et al., 2011; Lee et al., 2013). TTP functions as a tumor suppressor by inhibiting expression of cancer-related genes that encode AREs in their mRNA 3'UTRs. TTP target mRNAs encode inflammatory cytokines, cell growth factors, angiogenesis, apoptosis, and differentiation-related factors. For instance, TTP downregulates VEGF levels by reducing VEGF mRNA accumulation; this, in turn, decreases angiogenesis and reduces CRC growth (López de Silanes et al., 2003; Lee et al., 2010, 2018). TTP also regulates the expression of cancer-related proteins (Fos, Myc, COX-2, cIAP2, E2F1, Bcl-2, Mcl-1, LATS2, Lin28, and Cyclin D1), which contribute to inflammation, apoptosis, and angiogenesis in CRC (Lee et al., 2010, 2018; Sobolewski et al., 2015). Accordingly, TTP downregulation occurs at early stages of tumorigenesis and ectopic expression of TTP in CRC attenuates cell proliferation (Sobolewski et al., 2015).

\section{Xenografts Studies}

The inverse correlation between the expression levels of TTP and VEGF has been seen in nude mice, where tumor growth and angiogenesis are inhibited by TTP-mediated VEGF downregulation (Lee et al., 2010). Besides, TTP knockout mouse model develops multiple inflammatory syndromes due to the increased expression of tumor necrosis factor, $C O X-2$ and other pro-inflammatory proteins (Sobolewski et al., 2015).

\section{miRNA Control}

miR-29a downregulates TTP in a breast cancer model and is known to be upregulated in colon cancer (Sobolewski et al., 2015).

\section{Clinical Relevance}

Fallahi et al. have shown that TTP reduction is associated with poor prognosis, tumor aggressiveness and necrosis (Fallahi et al., 2014). The pharmacologic activation of TTP may limit colon cancer growth when patients present resistance to antiVEGF therapies (Lee et al., 2010). In this regard, some therapies have been developed to activate TTP. For instance, Resveratrol, a natural anti-cancer compound, induces cellular apoptosis and decreases migration and invasion by activating TTP and regulating other cancer pathways (MYC, KRAS, and FOS) (Lee et al., 2018). Another agent aiming to restore TTP expression in cancer cells is Vorinostat $^{\circledR}$ (SAHA), already in phase 1 clinical trial (Sobolewski et al., 2015). Another option to increase TTP expression is the use of histone deacetylase inhibitors (HDAC inhibitors), which can restore TTP expression at the transcriptional level (Sobolewski et al., 2015).

\section{HNRNPS}

\section{General Features}

Heterogeneous nuclear ribonucleoproteins (hnRNPs) are normally localized in the nucleus; however, some may shuttle between the nucleus and cytoplasm due to their nuclear export signals. They are known as pre-mRNA/mRNA binding proteins that participate in important cellular mechanisms, such as DNA repair, response to hypoxia, splicing, nucleocytoplasmic transport, apoptosis and transcriptional and translational regulation (Ushigome et al., 2005; Hope and Murray, 2011; Lai et al., 2016). Quantitative and qualitative alterations of hnRNPs have shown to disturb cellular functions and facilitate malignant transformation (Ushigome et al., 2005).

To date, at least 20 major hnRNP proteins, from hnRNP Al to U, have been identified in human cells (Ushigome et al., 2005). All members of the hnRNP family share a similar protein structure, consisting of at least one RRM combined with other auxiliary domain: RGG box or the acidic domain responsible for proteinprotein interactions (Lai et al., 2016). Given that all hnRNPs belong to the same family, their phenotypic impact is likely similar (Hope and Murray, 2011; Budak et al., 2017). Despite their great importance, few studies have been focused on cancer and much less on CRC. Table 2 summarizes their function and effect in CRC.

\section{TIA1}

\section{General Features}

T-cell intracellular Antigen-1 (TIA1) is a cytoplasmic granuleassociated RBP which contains three RRMs (Zlobec et al., 2010; Hamdollah Zadeh et al., 2014; Yang et al., 2014). TIA1 is linked to multiple biological processes associated with RNA metabolism and plays an important role in the regulation of gene expression, predominantly under conditions of cellular stress (Liu et al., 2014; Yang et al., 2014). TIA1 is alternatively spliced in exon 5 to form two isoforms (short and long), both of them reported to be expressed in cytolytic cells. TIA1 inhibits both transcriptional and posttranscriptional events of many transcripts involved in cancer cell proliferation, apoptosis, angiogenesis, invasiveness, and metastasis as well as in immune evasion (Hamdollah Zadeh et al., 2014; Liu Z. P. et al., 2017). For example, TIA1 can promote cell apoptosis by regulating Fas alternative splicing, while also enhancing NK cell 
TABLE 2 | Function and effect of hnRNPs in CRC.

\begin{tabular}{|c|c|c|c|}
\hline hnRNP & Function & Effect in CRC & Reference \\
\hline Al & $\begin{array}{l}\text { - Unwinds intramolecular folded-back } \\
\text { quadruplex structures of telomere repeats } \\
\text { and G-rich short tandem repeats (STRs). } \\
\text { - Abrogates DNA synthesis arrest. } \\
\text { - Promotes a protective effect } \\
\text { against apoptosis. }\end{array}$ & $\begin{array}{l}\text { - A potential biomarker. It has a significant } \\
\text { cytoplasmic immunoreaction in tumor cells. }\end{array}$ & $\begin{array}{l}\text { Ushigome et al., 2005; Zhang et al., } \\
\text { 2006; Hope and Murray, } 2011\end{array}$ \\
\hline A18 & $\begin{array}{l}\text { - Promotes inflammatory responses when } \\
\text { present extracellularly. }\end{array}$ & $\begin{array}{l}\text { - Higher hnRNPA18 expression in CRC cells could } \\
\text { be used as an independent prognostic marker. }\end{array}$ & $\begin{array}{l}\text { Sakurai et al., 2014; Chang et al., } \\
\text { 2016; Jang et al., } 2017\end{array}$ \\
\hline $\mathrm{D}$ & $\begin{array}{l}\text { - Destabilizes RNA and regulates expression of } \\
\text { pro-inflammatory Cytokines, } \\
\text { proto-oncogenes, and regulators of } \\
\text { apoptosis, and the cell cycle. } \\
\text { - Enhances mRNA stability and translation. }\end{array}$ & $\begin{array}{l}\text { - Indirectly regulates cancer-related mRNAs by } \\
\text { inhibiting Dicer-mediated mature miRNA } \\
\text { formation. HnRNPD binds to Dicer mRNA } \\
\text { reducing its stability. An inverse correlation } \\
\text { between Dicer and hnRNPD expression has been } \\
\text { observed in CRC tissues. }\end{array}$ & $\begin{array}{l}\text { Dixon, 2004; Zucconi and Wilson, } \\
\text { 2011; Ciafrè and Galardi, 2013; Dai } \\
\text { et al., } 2019\end{array}$ \\
\hline DL & $\begin{array}{l}\text { - Acts as a transcriptional regulator. } \\
\text { - Promotes transcription repression. } \\
\text { - Stimulates transcription activation in } \\
\text { differentiated myotubes. }\end{array}$ & $\begin{array}{l}\text { - Confers growth advantage through its ability to } \\
\text { promote cell cycle progression. }\end{array}$ & $\begin{array}{l}\text { Balasubramani et al., 2006; } \\
\text { Rappaport et al., } 2017\end{array}$ \\
\hline $\mathrm{F}$ & $\begin{array}{l}\text { - Plays a role in the regulation of alternative } \\
\text { splicing events. } \\
\text { - Binds G-rich sequences in pre-mRNAs and } \\
\text { keeps target RNA in an unfolded state. }\end{array}$ & - Involved in early CRC genesis. & $\begin{array}{l}\text { Balasubramani et al., 2006; } \\
\text { Rappaport et al., } 2017\end{array}$ \\
\hline $\mathrm{H}$ & $\begin{array}{l}\text { - Mediates pre-mRNA alternative } \\
\text { splicing regulation. }\end{array}$ & $\begin{array}{l}\text { - } \mathrm{hnRNPH} \text { is associated with good prognosis, } \\
\text { especially in left-sided (distal) colonic tumors and } \\
\text { rectal tumors. }\end{array}$ & $\begin{array}{l}\text { Hope and Murray, 2011; Rappaport } \\
\text { et al., } 2017\end{array}$ \\
\hline I & $\begin{array}{l}\text { - Activates exon skipping of its own pre-mRNA } \\
\text { during muscle cell differentiation. }\end{array}$ & $\begin{array}{l}\text { - Silences Notch signaling pathway, which is a } \\
\text { critical mediator of stem cell proliferation and } \\
\text { differentiation of colonic epithelium. }\end{array}$ & $\begin{array}{l}\text { Hope and Murray, 2011; Jin et al., } \\
\text { 2017; Rappaport et al., } 2017\end{array}$ \\
\hline K & $\begin{array}{l}\text { - Plays an important role in TP53 response to } \\
\text { DNA damage, acting at both transcription } \\
\text { activation, and repression. }\end{array}$ & $\begin{array}{l}\text { - Could be used as a poor prognosis marker. } \\
\text { Altered expression and cellular localization } \\
\text { correlates with CRC tumor stage. }\end{array}$ & $\begin{array}{l}\text { Hope and Murray, 2011; Guo et al., } \\
\text { 2012; Sugimasa et al., 2015; Zhang } \\
\text { et al., 2016; Budak et al., 2017; } \\
\text { Rappaport et al., } 2017\end{array}$ \\
\hline M & $\begin{array}{l}\text { - Acts as a receptor for carcinoembryonic } \\
\text { antigen in Kupffer cells } \\
\text { - Initiates a series of signaling events leading to } \\
\text { tyrosine phosphorylation of proteins and } \\
\text { induction of IL-1 alpha, IL-6, IL-10, and } \\
\text { tumor necrosis factor alpha. }\end{array}$ & $\begin{array}{l}\text { - Positively correlates with proliferation, invasion } \\
\text { and metastasis of CRC cells. }\end{array}$ & Chen et al., 2013 \\
\hline $\mathrm{L}$ & $\begin{array}{l}\text { - Involved in the synthesis of new } \\
\text { blood vessels. }\end{array}$ & - Promotes angiogenesis in CRC cells. & Hope and Murray, 2011 \\
\hline Q & $\begin{array}{l}\text { - Promotes MYC mRNA stability } \\
\text { - Modulates the posttranscriptional } \mathrm{C} \text { to } U \\
\text { RNA-editing of the APOB mRNA. }\end{array}$ & $\begin{array}{l}\text { - Increases cell proliferation and contribute } \\
\text { to tumorigenesis. }\end{array}$ & $\begin{array}{l}\text { Lai et al., 2016; Rappaport et al., } \\
\qquad 2017\end{array}$ \\
\hline U & - Repairs double-strand DNA. & $\begin{array}{l}\text { - Aberrantly found in the nucleus of CRC cells, } \\
\text { compared with normal colonic epithelium. }\end{array}$ & Hope and Murray, 2011 \\
\hline
\end{tabular}

cytotoxic activity (Zlobec et al., 2010; Liu Z. P. et al., 2017). TIA1 is downregulated at the protein level in CRC, which is therefore considered as a tumor suppressor RBP (Liu Y. et al., 2017).

\section{Xenograft Studies and miRNA Control}

TIA1 is a direct target of miR-19a in CRC, where is highly expressed (Liu Y. et al., 2017). miR-19a is part of a family known as mir17-92, which possess several cellular functions as survival, proliferation, differentiation, and formation of new blood vessels (Olive et al., 2009). This miRNA promotes cell proliferation and migration in vitro and accelerates tumor growth in xenografed mice. miR-19a binds directly to the $3^{\prime}$-UTR of TIA1 mRNA inhibiting TIA1 cancer suppressive features. Suppression of miR19a activity could increase cellular levels of TIA 1 , therefore impairing cancer-related cellular processes (Liu Y. et al., 2017).

\section{Clinical Relevance}

TIA1 is a robust prognostic immunological biomarker in CRC and particularly in tumors with marked cytotoxic CD8+ tumor-infiltrating lymphocytes (TILs). Increased numbers of 
TIA1 positive TILs is associated with an improved clinical outcome representing an independent prognostic factor (Zlobec et al., 2010). TIA1 can also be used to supplement prognostic information related to TNM (tumor, node, and metastases) stage and adjuvant therapy in mismatch repair-proficient colorectal cancer patients (Liu Y. et al., 2017).

\section{KHDRBS1}

\section{General Features}

$\mathrm{KH}$ RNA binding domain containing signal transduction associated 1 (KHDRBS1) protein or Src-associated in mitosis 68 $\mathrm{kDa}$ protein is part of STAR family KH domain-containing RBPs (Sánchez-Jiménez and Sánchez-Margalet, 2013). It is a substrate for Src kinases, which are often activated in human cancers. KHDRBS1 is usually a nuclear protein, which is a mitogene and is also involved in transformation and tumorigenesis. This RBP plays a major protagonist in the life cycle of RNA molecules. Besides, KHDRBS1 regulates the alternative splicing of several genes, most of them involved in human cancer, such as CD44, Bcl-xl, Sgce, SMN2, SF2/ASF, and Cyclin D1. KHDRBS1 also participates in early cellular responses to DNA damage by controlling the signaling cascade that links DNA damage recognition in the nucleus to NF- $\mathrm{BB}$ liberation and activation in the cytoplasm. Accordingly, KHDRBS1 downregulation promotes self-destruction of colon cancer cells under exposure to DNA-damaging agents. KHDRBS1 is therefore important for CRC development and survival (Fu et al., 2016).

\section{Xenograft Studies}

KHDRBS1 null mice produced delays in colon tumor growth, metastasis, cell migration, and extremely sensitiveness to agents that cause DNA damage (Lukong and Richard, 2007; Fu et al., 2016).

\section{Clinical Relevance}

Several studies have reported KHDRBS1 to be overexpressed in CRC tissues. KHDRBS1 nuclear localization and overexpression is correlated with poorly differentiated cancer cells, advanced T, $\mathrm{N}$, and M1 stage. Poor prognosis and a higher risk of recurrence have been seen in patients with high levels of this protein or nuclear localization (Liao et al., 2013; Fu et al., 2016).

\section{CPEB4}

\section{General Features}

Cytoplasmic Polyadenylation Element Binding Protein 4 (CPEB4) is a ubiquitous cytoplasmic zinc-finger RBP (Zhong et al., 2015; He et al., 2017; Rappaport et al., 2017). CPB4 gene is localized on chromosome $5 \mathrm{q} 35$ and encodes a protein composed of 729 amino acids (He et al., 2017). CPEB4 can modulate the cellular epigenetic profile and influence several biological activities such as cell proliferation and differentiation, chromatinremodeling, and chromosome segregation (Zhong et al., 2015; He et al., 2017). Furthermore, CPEB4 recruits translational repression or polyadenylation machinery, which targets mRNAs that regulate mitotic and meiotic cell cycle and senescence (Cortés-Guiral et al., 2017; He et al., 2017). Importantly, CPEB4 is highly expressed in a variety of malignant tumors, including CRC, promoting tumor proliferation, invasion, migration, and vascularization (Zhong et al., 2015; Cortés-Guiral et al., 2017; He et al., 2017). CPEB4 can also influence apoptosis of tumoral cells by modulating the expressions of B-cell lymphoma extra-large (Bcl-XL) and B-cell lymphoma-2-associated X (Bax) proteins. CPEB4 knockdown increases Bax expression but decreases $\mathrm{Bcl}-\mathrm{XL}$ expression. Changes in the homeostatic balance of Bax and Bcl-XL lead to a deregulation of apoptosis during tumor development. In addition, three parameters are considered as prognostic markers in CRC: (i) age, (ii) body tumor location, and (iii) Bax/Bcl-2 ratio (Zhong et al., 2015).

\section{miRNA Control}

Recent studies have shown miR-203, a tumor suppressive miRNA, significantly decreased in colorectal cancers. miR203 inhibits cancer growth and enhances cell apoptosis by suppressing CPEB4 expression post-transcriptionally (Zhong et al., 2015; Cortés-Guiral et al., 2017). Hence, miR-203-mediated CPEB4 degradation might be a novel strategy in CRC treatment (Zhong et al., 2015).

\section{Clinical Relevance}

CPEB4 is aberrantly expressed in CRC tissues and correlates with tumor progression and poor overall survival in CRC patients. Thus, detecting CPEB4 expression in CRC tissues or peripheral blood might be used as an additional parameter to identify patients with a high risk of tumor invasiveness and/or metastasis. Patients with these characteristics could be considered for more personalized and aggressive treatment (Zhong et al., 2015; He et al., 2017).

\section{AGO}

\section{General Features}

The Argonaute (AGO) proteins are fundamental components of RNA-induced silencing complexes (RISC) and RNA interference (RNAi) machinery, which induce endonuclease cleavage of mRNA and miRNA passenger strand. Currently, two subfamilies with 4 Argonaute-like proteins within each have been described: (i) eIF2C/AGO subfamily with AGO1, AGO2, AGO3, and AGO4 and (ii) PIWI subfamily with PIWIL1, PIWIL2, PIWIL3, and PIWIL4. AGO subfamily genes are ubiquitously expressed and are regulated in a cell-context-dependent manner (Li et al., 2010; Rüdel et al., 2011).

Small interfering RNAs (siRNAs) and/or miRNAs are used by Ago proteins as silencing mechanisms in both transcriptional and posttranscriptional processes. Overexpression of AGO members has been associated with excessive growth and programmed cell death inhibition of cancer stem cells. Specifically, increased expression of AGO2-4 and PIWIL4 has been associated with colon cancer occurrence in advanced tumors with distant metastasis (Li et al., 2010). 


\section{CSDE1}

\section{General Features}

Cold shock domain containing E1 (CSDE1), formerly named Upstream of the NRAS (UNR), is an RBP composed of 798 amino acids with 5 cold shock domains. CSDE1 gene is located on chromosome 1p13.2 upstream of the NRAS locus. CSDE1 has been shown to regulate mRNA stability and translation of several oncogenes, such as c-MYC, c-FOS, VIM, PTEN, among many others, in melanoma, breast, pancreatic and prostate cancer (Grosset et al., 2000; Evans et al., 2003; Chang et al., 2004; Wurth et al., 2016). Recently, MartinezUseros et al. have reported key oncogenic features of CSDE1 in CRC. According to this study, CSDE1 is overexpressed in several CRC-derived cell lines, paired tumor samples, colonospheres and cell cultures originated from metastatic lesions. In contrast, CSDE1 downregulation increases sensitivity to apoptosis and decrease invasiveness, cell viability and migration by an EMT regulation process. In addition, CSDE1 expression positively correlates with $c-M Y C$ expression in CRC samples and cell lines, supporting its role as a CRC oncogene (Martinez-Useros et al., 2019).

\section{Clinical Relevance}

Martinez-Useros et al. also demonstrated a possible role of CSDE1 as a clinical marker, predicting poor outcome of CRC patients. Patients with high CSDE1 expression presented shorter mean survival than patients with low expression. Although the sample size to achieved

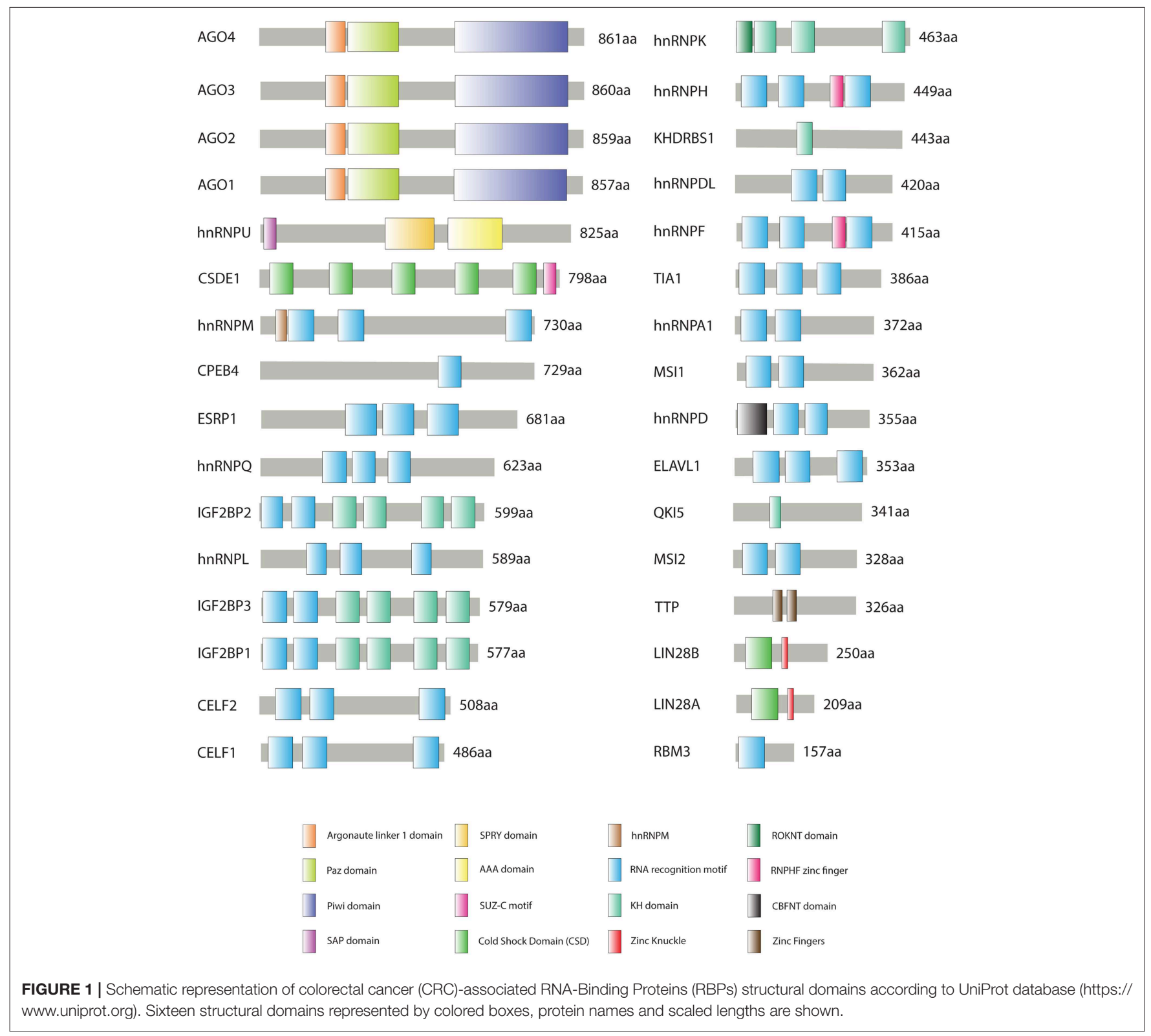


this conclusion was small, an in silico analysis using The Cancer Genome Atlas (TCGA)-Colorectal Cancer Dataset showed similar results: patients with high CSDE1 expression presented shorter mean progressionfree survival than patients with low CSDE1 expression (Martinez-Useros et al., 2019).

\section{COMMON FEATURES OF ALL COLON CANCER RELATED RBPS}

RBPs are pivotal members of the posttranscriptional process and key players of RNA regulons. Within this notion, RBPs regulate mRNAs that encode functionally related proteins through a RNP-driven mechanism. Genomic alterations of RBPs could therefore produce erroneous conformation of these RNP complexes leading to atypical protein expression and cancer development (Castello et al., 2016; Wurth et al., 2016; Pereira et al., 2017). To shed light on CRC RNA regulons, we studied CRC RBPs common features related to their protein domains, protein-protein interactions, and common RNA targets. In addition, we also organized CRC
RBPs oncogenic capabilities into the hallmarks of cancer (Hanahan and Weinberg, 2011).

Figure 1 shows all CRC-associated RBPs and their protein domains according to UniProt database (https://www.uniprot. org/) (The UniProt Consortium, 2019); we detected 16 protein domains, of which 13 are RNA-binding domains: RRM, CSD, KH domain, Zinc finger, etc. RRM is the most prevalent domain of the CRC-related RBPs, followed by $\mathrm{KH}$ domain and CSD. To detect protein-protein interactions, we generated an interaction network using STRING database (Szklarczyk et al., 2017) with experiment scores $>0.9$. Seventeen out Thirty-Two RBPs form a complex interaction network (Figure 2A); we also observed interactions between all AGO members.

Over the past decade, high-throughput technologies have been developed to identify RBP biding sites in vivo (ultraviolet crosslinking followed by immunoprecipitation and sequencing-CLIP) and mRNA translation performance (Ribosome profiling-Ribo-seq) (Ingolia et al., 2009). Recently, Zhu et al. integrated several datasets from these highthroughput technologies to investigate post-transcriptional regulatory processes mediated by RBPs through a database
A

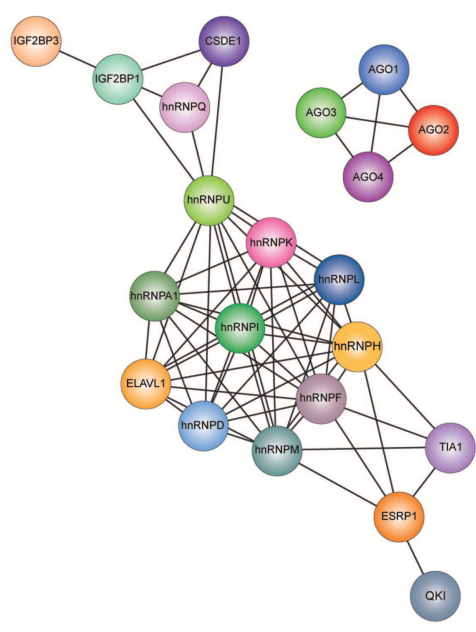

B

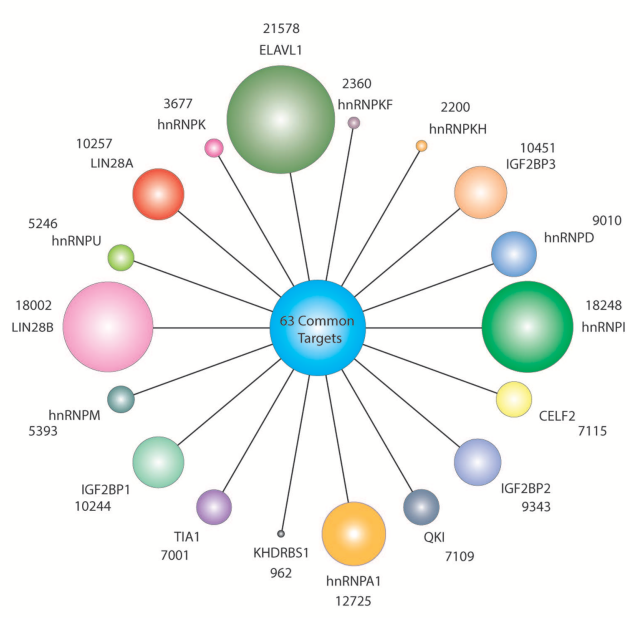

C

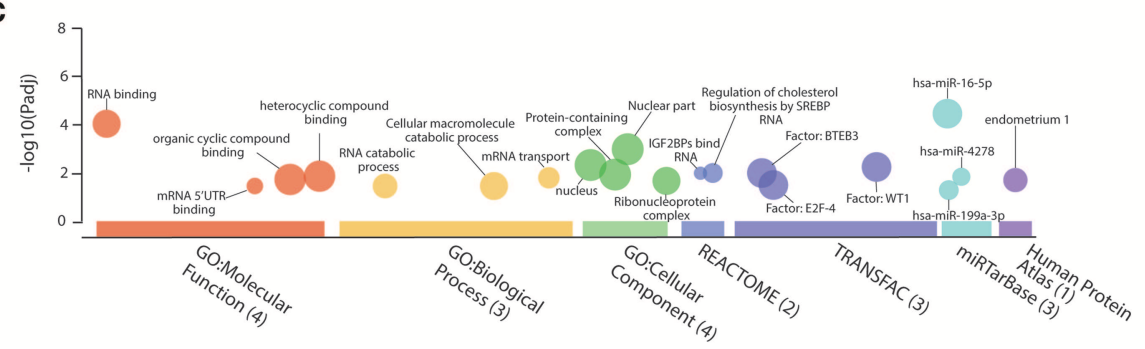

FIGURE 2 | Common features of colorectal cancer (CRC)-related RNA-Binding Proteins (RBPs). (A) CRC RBPs RNA targets according to POSTAR2 database. Circle sizes are correlated with the number of targets of each protein; shared RNA targets are shown in the middle. (B) A network showing CRC RBPs protein-protein interactions from experimental data and databases (interaction score: > 0.9). (C) Gene set enrichment analysis showing all significantly enriched terms concerning Gene Ontology (Molecular Function, Biological Process, and Cellular Component), Reactome, Transfac, miRTasBase, and Human Protein Atlas through g:Profiler (https://biit.cs.ut.ee/gprofiler/gost). The size of the circle is correlated with the number of genes overrepresented in association with certain type of molecular function or biological process. P-value adjusted (Padj) for multiple testing using Benjamini-Hochberg method. 


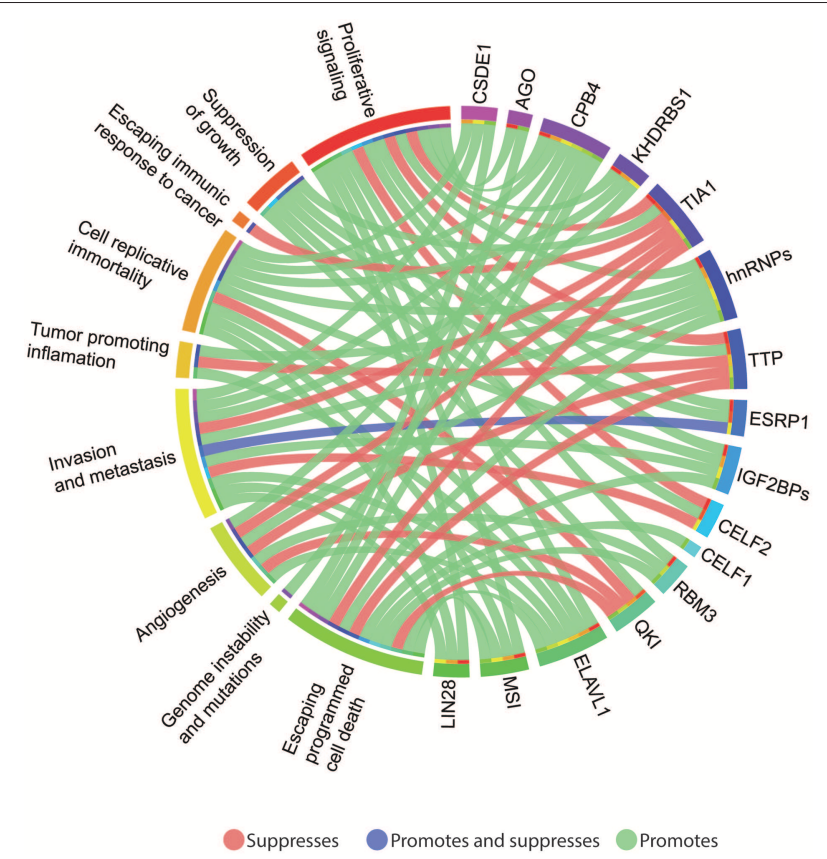

FIGURE 3 | Circos plot (http://circos.ca/intro/features/) depicting the relationships between colorectal cancer (CRC) RNA-binding proteins (RBPs) and the hallmarks of cancer. Outer circle: right, CRC RBPs and left, hallmarks of cancer associated with each studied protein. Green-colored links indicate a cancer promoting activity, while red links, suppression, and the blue-colored link denotes both, promotion and suppression activity. named POSTAR2 (http://lulab.life.tsinghua.edu.cn/postar/). This allowed us to identify all RNA targets of 18 out 32 CRC-related RBPs (Figure 2B). For example, ELAVL1 could bind to 21578 RNAs, while KHDRBS1 interacts with 962. A post-hoc analysis revealed 63 common targets (Supplementary Table 1). Interestingly, these RNAs encode proteins or participate in RNA-related processes, such as RNA binding or mRNA transport (Figure 2C), adding another layer to the RNA regulon model: interacting RBPs that regulate RNAs implicated in RNA-associated processes. In fact, $30 \%$ of these common targets $(n=19)$ are also RBPs (Figure 2C) (Culjkovic-Kraljacic and Borden, 2018). However, some well-known cancer driver genes, such as MYC and COX2 are common targets of 11 and 7 , respectively out of 18 CRC RBPs.

Finally, to better understand the oncogenic potential of the aforementioned RBPs, their capabilities were organized according to the hallmarks of cancer. As shown in Figure 3, most RBPs (11 out of 16) act as oncogenes and only 5 (TIA1, TTP, QKI, ESRP1, CELF2, and QKI) present tumor suppressive abilities. Worthy of note, TIA 1 is the only RBP that suppresses the ability of cancer cells to escape immune response by enhancing NK cell cytotoxic activity (Zlobec et al., 2010; Liu Z. P. et al., 2017); also, CPEB4 is the only RBP that promotes genome instability by influencing chromatin-remodeling (Negrini et al., 2010; Zhong et al., 2015; He et al., 2017).

\section{CONCLUDING REMARKS AND PERSPECTIVES}

Several efforts have been devoted to decipher the molecular basis behind the carcinogenesis process. Most of this knowledge was achieved by studying DNA and protein function, leaving posttranscription under-investigated. In this regard, RBPs play a significant role in controlling gene expression through complex interconnected networks named RNA regulons. Consequently, RBPs alterations could greatly disrupt cellular homeostasis promoting cancer development.

We believe this work offers a comprehensive list of all CRC-associated RBPs, including their individual features to common interactions and targets. However, we only found in the literature $35 \mathrm{RBPs}$ out of 1,393 having oncogenic roles in CRC; a comprehensive characterization of RBPs is therefore still missing. To shed light on this matter, not only the identification of the CRC-RBPome should be prioritized, but also its dynamics concerning CRC RNA regulons implicated in cancer progression. As we shown in Figure 2, these interactions are highly complex and more research is needed to identify key therapeutic interactions. To date, no RBP-based drug has been developed to treat CRC, according to the Open Target Platform (https://www.targetvalidation.org).

RNA-based research is generating large datasets from highthroughput technologies, such CLIP, Ribo-seq or interactome capture. To successfully understand this complexity, all this data should be compiled and analyzed by bioinformatics and systems biology approaches, such as POSTAR2 or the ones developed by the RNA Bioinformatics Center (Backofen et al., 2017). In addition, large datasets, such as The Cancer Genome Atlas (Tomczak et al., 2015), the Human Protein Atlas (Pontén et al., 2008) or Depmap (Yu et al., 2016) could be exploited to identify key RBPs that, with further research, could be used as CRC biomarkers or new therapeutic targets.

\section{AUTHOR CONTRIBUTIONS}

JG-C and SG conceived the subject and wrote the manuscript. $\mathrm{CP}$ supervised the project and provided conceptual advice and valuable scientific input. AL-C, IA-C, PG-R, AP-V, VY, AZ, and PL made a substantial contribution to the structure and design of the manuscript.

\section{SUPPLEMENTARY MATERIAL}

The Supplementary Material for this article can be found online at: https://www.frontiersin.org/articles/10.3389/fmolb. 2019.00065/full\#supplementary-material 


\section{REFERENCES}

Abdelmohsen, K., Srikantan, S., Kuwano, Y., and Gorospe, M. (2008). miR-519 reduces cell proliferation by lowering RNA-binding protein HuR levels. Proc. Natl. Acad. Sci. U.S.A. 105, 20297-20302. doi: 10.1073/pnas.0809376106

Akaike, Y., Masuda, K., Kuwano, Y., Nishida, K., Kajita, K., Kurokawa, K., et al. (2014). HuR regulates alternative splicing of the TRA2 gene in human colon cancer cells under oxidative stress. Mol. Cell. Biol. 34, 2857-2873. doi: 10.1128/MCB.00333-14

Al-Haidari, A., Algaber, A., Madhi, R., Syk, I., and Thorlacius, H. (2018). MiR-155-5p controls colon cancer cell migration via post-transcriptional regulation of Human Antigen R (HuR). Cancer Lett. 421, 145-151. doi: 10.1016/j.canlet.2018.02.026

Backofen, R., Engelhardt, J., Erxleben, A., Fallmann, J., Grüning, B., Ohler, U., et al. (2017). RNA-bioinformatics: tools, services and databases for the analysis of RNA-based regulation. J. Biotechnol. 261, 76-84. doi: 10.1016/j.jbiotec.2017.05.019

Badawi, A., Hehlgans, S., Pfeilschifter, J., Rödel, F., and Eberhardt, W. (2017). Silencing of the mRNA-binding protein HuR increases the sensitivity of colorectal cancer cells to ionizing radiation through upregulation of caspase-2. Cancer Lett. 393, 103-112. doi: 10.1016/j.canlet.2017.02.010

Balasubramani, M., Day, B. W., Schoen, R. E., and Getzenberg, R. H. (2006). Altered expression and localization of creatine kinase $\mathrm{B}$, heterogeneous nuclear ribonucleoprotein $\mathrm{F}$, and high mobility group box 1 protein in the nuclear matrix associated with colon cancer. Cancer Res. 66, 763-769. doi: 10.1158/0008-5472.CAN-05-3771

Blanco, F. F., Preet, R., Aguado, A., Vishwakarma, V., Stevens, L. E., Vyas, A., et al. (2016). Impact of HuR inhibition by the small molecule MS444 on colorectal cancer cell tumorigenesis. Oncotarget 7, 74043-74058. doi: 10.18632 /oncotarget.12189

Bray, F., Ferlay, J., Soerjomataram, I., Siegel, R. L., Torre, L. A., and Jemal, A. (2018). Global cancer statistics 2018: GLOBOCAN estimates of incidence and mortality worldwide for 36 cancers in 185 countries. CA Cancer J. Clin. 68, 394-424. doi: 10.3322/caac. 21492

Brennan, C. M., and Steitz, J. A. (2001). HuR and mRNA stability. Cell. Mol. Life Sci. 58, 266-277. doi: 10.1007/PL00000854

Budak, G., Srivastava, R., and Janga, S. C. (2017). Seten: a tool for systematic identification and comparison of processes, phenotypes, and diseases associated with RNA-binding proteins from condition-specific CLIP-seq profiles. RNA 23, 836-846. doi: 10.1261/rna.059089.116

Burd, C., and Dreyfuss, G. (1994). Conserved structures and diversity of functions of RNA-binding proteins. Science 265, 615-621. doi: 10.1126/science.8036511

Carrick, D. M., and Blackshear, P. J. (2007). Comparative expression of tristetraprolin (TTP) family member transcripts in normal human tissues and cancer cell lines. Arch. Biochem. Biophys. 462, 278-285. doi: 10.1016/j.abb.2007.04.011

Castello, A., Fischer, B., Frese, C. K., Horos, R., Alleaume, A. M., Foehr, S., et al. (2016). Comprehensive identification of RNA-binding domains in human cells. Mol. Cell 63, 696-710. doi: 10.1016/j.molcel.2016.06.029

Cha, H. J., Lee, H. H., Chae, S. W., Cho, W. J., Kim, Y. M., Choi, H. J., et al. (2011). Tristetraprolin downregulates the expression of both VEGF and COX-2 in human colon cancer. Hepatogastroenterology 58, 790-795.

Chang, E. T., Parekh, P. R., Yang, Q., Nguyen, D. M., and Carrier, F. (2016). Heterogenous ribonucleoprotein A18 (hnRNP A18) promotes tumor growth by increasing protein translation of selected transcripts in cancer cells. Oncotarget 7, 10578-10593. doi: 10.18632/oncotarget.7020

Chang, T. C., Yamashita, A., Chen, C. Y. A., Yamashita, Y., Zhu, W., Durdan, S., et al. (2004). UNR, a new partner of poly(A)-binding protein, plays a key role in translationally coupled mRNA turnover mediated by the c-fos major codingregion determinant. Genes Dev. 18, 2010-2023. doi: 10.1101/gad.1219104

Chappell, S. A., and Mauro, V. P. (2003). The internal ribosome entry site (IRES) contained within the RNA-binding motif protein 3 (Rbm3) mRNA is composed of functionally distinct elements. J. Biol. Chem. 278, 33793-33800. doi: 10.1074/jbc.M303495200

Chen, L., Xie, Y., Li, X., Gu, L., Gao, Y., Tang, L., et al. (2017). Prognostic value of high iMP3 expression in solid tumors: a meta-analysis. Oncol. Targets Ther. 10, 2849-2863. doi: 10.2147/OTT.S128810
Chen, S., Zhang, J., Duan, L., Zhang, Y., Li, C., Liu, D., et al. (2013). Identification of HnRNP $\mathrm{M}$ as a novel biomarker for colorectal carcinoma by quantitative proteomics. Am. J. Physiol. Gastrointest. Liver Physiol. 306, G394-G403. doi: 10.1152/ajpgi.00328.2013

Cheng, D. L., Xiang, Y. Y., Ji, L. J., and Lu, X. J. (2015). Competing endogenous RNA interplay in cancer: mechanism, methodology, and perspectives. Tumor Biol. 36, 479-488. doi: 10.1007/s13277-015-3093-z

Choi, D. K., Ito, T., Tsukahara, F., Hirai, M., and Sakaki, Y. (1999). Developmentally-regulated expression of mNapor encoding an apoptosis-induced ELAV-type RNA binding protein. Gene 237, 135-142. doi: 10.1016/S0378-1119(99)00312-1

Ciafrè, S. A., and Galardi, S. (2013). microRNAs and RNA-binding proteins: a complex network of interactions and reciprocal regulations in cancer. RNA Biol. 10, 927-935. doi: 10.4161/rna.24641

Cortés-Guiral, D., Pastor-Iodate, C., Díaz del Arco, C., del Puerto-Nevado, L., and Fernández-Aceñero, M. J. (2017). CPEB4 immunohistochemical expression is associated to prognosis in stage IV colorectal carcinoma. Pathol. Res. Pract. 213, 639-642. doi: 10.1016/j.prp.2017.04.020

Cui, Y. H., Xiao, L., Rao, J. N., Zou, T., Liu, L., Chen, Y., et al. (2012). miR-503 represses CUG-binding protein 1 translation by recruiting CUGBP1 mRNA to processing bodies. Mol. Biol. Cell. 23, 151-162. doi: 10.1091/mbc.e11-05-0456

Culjkovic-Kraljacic, B., and Borden, K. L. B. (2018). The impact of posttranscriptional control: better living through RNA regulons. Front. Genet. 9:512. doi: 10.3389/fgene.2018.00512

Dai, W., Mu, L., Cui, Y., Li, Y., Chen, P., Xie, H., et al. (2019). Berberine promotes apoptosis of colorectal cancer via regulation of the long non-coding RNA (lncRNA) cancer susceptibility candidate 2 (CASC2)/AU-binding factor 1 (AUF1)/B-Cell CLL/ lymphoma 2 (Bcl-2) axis. Med. Sci. Monit. 25, 730-738. doi: 10.12659/MSM.912082

Darbelli, L., Vogel, G., Almazan, G., and Richard, S. (2016). Quaking regulates neurofascin 155 expression for myelin and axoglial junction maintenance. $J$. Neurosci. 36, 4106-4120. doi: 10.1523/JNEUROSCI.3529-15.2016

de Sousa Abreu, R., Sanchez-Diaz, P. C., Vogel, C., Burns, S. C., Ko, D., Burton, T. L., et al. (2009). Genomic analyses of musashil downstream targets show a strong association with cancer-related processes. J. Biol. Chem. 284, 12125-12135. doi: 10.1074/jbc.M809605200

Degrauwe, N., Schlumpf, T. B., Janiszewska, M., Martin, P., Cauderay, A., Provero, P., et al. (2016). The RNA binding protein IMP2 preserves glioblastoma stem cells by preventing let-7 target gene silencing. Cell Rep. 15, 1634-1647. doi: 10.1016/j.celrep.2016.04.086

Deloria, A. J., Höflmayer, D., Kienzl, P., Łopatecka, J., Sampl, S., Klimpfinger, M., et al. (2016). Epithelial splicing regulatory protein 1 and 2 paralogues correlate with splice signatures and favorable outcome in human colorectal cancer. Oncotarget 7, 73800-73816. doi: 10.18632/oncotarget.12070

Denkert, C., Koch, I., Von Keyserlingk, N., Noske, A., Niesporek, S., Dietel, M., et al. (2006). Expression of the ELAV-like protein HuR in human colon cancer: association with tumor stage and cyclooxygenase-2. Mod. Pathol. 19, 1261-1269. doi: 10.1038/modpathol.3800645

Derry, J. M. J., Kerns, J. A., and Francke, U. (1995). RBM3, a novel human gene in Xp11.23 with a putative RNA-binding domain. Hum. Mol. Genet. 4, 2307-2311. doi: $10.1093 / \mathrm{hmg} / 4.12 .2307$

Dimitriadis, E., Trangas, T., Milatos, S., Foukas, P. G., Gioulbasanis, I., Courtis, N., et al. (2007). Expression of oncofetal RNA-binding protein CRD-BP/IMP1 predicts clinical outcome in colon cancer. Int. J. Cancer 121, 486-494. doi: $10.1002 / \mathrm{ijc} .22716$

Dixon, D. (2004). Dysregulated post-transcriptional control of COX2 gene expression in cancer. Curr. Pharm. Des. 10, 635-646. doi: $10.2174 / 1381612043453171$

Dixon, D. A., Tolley, N. D., King, P. H., Nabors, L. B., McIntyre, T. M., Zimmerman, G. A., et al. (2001). Altered expression of the mRNA stability factor HuR promotes cyclooxygenase-2 expression in colon cancer cells. J. Clin. Invest. 108, 1657-1665. doi: 10.1172/ JCI12973

Dresios, J., Aschrafi, A., Owens, G. C., Vanderklish, P. W., Edelman, G. M., and Mauro, V. P. (2005). Cold stress-induced protein Rbm3 binds $60 \mathrm{~S}$ ribosomal subunits, alters microRNA levels, and enhances global protein synthesis. Proc. Natl. Acad. Sci. U.S.A. 102, 1865-1870. doi: 10.1073/pnas.0409764102 
Elcheva, I., Goswami, S., Noubissi, F. K., and Spiegelman, V. S. (2009). CRDBP protects the coding region of betaTrCP1 mRNA from miR-183-mediated degradation. Mol. Cell 35, 240-246. doi: 10.1016/j.molcel.2009.06.007

Evans, J. R., Mitchell, S. A., Spriggs, K. A., Ostrowski, J., Bomsztyk, K., Ostarek, D., et al. (2003). Members of the poly ( $\mathrm{rC}$ ) binding protein family stimulate the activity of the c-myc internal ribosome entry segment in vitro and in vivo. Oncogene 22, 8012-8020. doi: 10.1038/sj.onc. 1206645

Fagoonee, S., Picco, G., Orso, F., Arrigoni, A., Longo, D. L., Forni, M., et al. (2017). The RNA-binding protein ESRP1 promotes human colorectal cancer progression. Oncotarget 8, 10007-10024. doi: 10.18632/oncotarget.14318

Fallahi, M., Amelio, A. L., Cleveland, J. L., and Rounbehler, R. J. (2014). CREB targets define the gene expression signature of malignancies having reduced levels of the tumor suppressor tristetraprolin. PLOS ONE 9:e115517. doi: 10.1371/journal.pone.0115517

Fan, L. F., Dong, W. G., Jiang, C. Q., Xia, D., Liao, F., and Yu, Q. F. (2010). Expression of putative stem cell genes Musashi-1 and $\beta 1$-integrin in human colorectal adenomas and adenocarcinomas. Int. J. Colorectal Dis. 25, 17-23. doi: 10.1007/s00384-009-0791-2

Fan, X. C., and Steitz, J. A. (1998). Overexpression of HuR, a nuclear-cytoplasmic shuttling protein, increases the in vivo stability of ARE-containing mRNAs. EMBO J. 17, 3448-3460. doi: 10.1093/emboj/17.12.3448

Franceschini, A., Szklarczyk, D., Frankild, S., Kuhn, M., Simonovic, M., Roth, A., et al. (2012). STRING v9.1: protein-protein interaction networks, with increased coverage and integration. Nucleic Acids Res. 41, D808-D815. doi: 10.1093/nar/gks1094

Fu, K., Sun, X., Wier, E. M., Hodgson, A., Liu, Y., Sears, C. L., et al. (2016). Sam68/KHDRBS1 is critical for colon tumorigenesis by regulating genotoxic stress-induced NF-кB activation. Elife 5:e15018. doi: 10.7554/eLife.15018

Gao, C., Han, C., Yu, Q., Guan, Y., Li, N., Zhou, J., et al. (2015). Downregulation of Msi1 suppresses the growth of human colon cancer by targeting p21cip1. Int. J. Oncol. 46, 732-740. doi: 10.3892/ijo.2014.2749

Ghosh, M., Aguila, H. L., Michaud, J., Ai, Y., Wu, M. T., Hemmes, A., et al. (2009). Essential role of the RNA-binding protein HuR in progenitor cell survival in mice. J. Clin. Invest. 119, 3530-3543. doi: 10.1172/JCI38263

Glazer, R. I., Vo, D. T., and Penalva, L. O. (2012). Musashi1: an RBP with versatile functions in normal and cancer stem cells. Front. Biosci. 17, 54-64. doi: $10.2741 / 3915$

Grosset, C., Chen, C. Y., Xu, N., Sonenberg, N., Jacquemin-Sablon, H., and Shyu, A. B. (2000). A mechanism for translationally coupled mRNA turnover: interaction between the poly(A) tail and a c-fos RNA coding determinant via a protein complex. Cell 103, 29-40. doi: 10.1016/S0092-8674(00)00102-1

Guinney, J., Dienstmann, R., Wang, X., de Reyniès, A., Schlicker, A., Soneson, C., et al. (2015). The consensus molecular subtypes of colorectal cancer. Nat. Med. 21, 1350-1356. doi: 10.1038/nm.3967

Guo, Y., Chen, Y., Ito, H., Watanabe, A., Ge, X., Kodama, T., et al. (2006). Identification and characterization of lin-28 homolog B (LIN28B) in human hepatocellular carcinoma. Gene 384, 51-61. doi: 10.1016/j.gene.2006. 07.011

Guo, Y., Zhao, J., Bi, J., Wu, Q., Wang, X., and Lai, Q. (2012). Heterogeneous nuclear ribonucleoprotein $\mathrm{K}$ ( $\mathrm{hnRNP} \mathrm{K}$ ) is a tissue biomarker for detection of early Hepatocellular carcinoma in patients with cirrhosis. J. Hematol. Oncol. 5:37. doi: 10.1186/1756-8722-5-37

Hamdollah Zadeh, M. A., Amin, E., Hoareau-Aveilla, C., Domingo, E., Symonds, K. E., Ye, X., et al. (2014). Alternative splicing of TIA-1 in human colon cancer regulates VEGF isoform expression, angiogenesis, tumour growth and bevacizumab resistance. Mol. Oncol. 9, 167-178. doi: 10.1016/j.molonc.2014.07.017

Hamilton, K. E., Noubissi, F. K., Katti, P. S., Hahn, C. M., Davey, S. R., Lundsmith, E. T., et al. (2013). IMP1 promotes tumor growth, dissemination and a tumorinitiating cell phenotype in colorectal cancer cell xenografts. Carcinogenesis 34, 2647-2654. doi: 10.1093/carcin/bgt217

Hanahan, D., and Weinberg, R. A. (2011). Hallmarks of cancer: the next generation. Cell 144, 646-674. doi: 10.1016/j.cell.2011.02.013

He, B., Gao, S. Q., Huang, L. D., Huang, Y. H., Zhang, Q. Y., Zhou, M. T., et al. (2015). MicroRNA-155 promotes the proliferation and invasion abilities of colon cancer cells by targeting quaking. Mol. Med. Rep. 11, 2355-2359. doi: 10.3892/mmr.2014.2994
He, X., Lin, X., Cai, M., Fan, D., Chen, X., Wang, L., et al. (2017). High expression of cytoplasmic polyadenylation element-binding protein 4 correlates with poor prognosis of patients with colorectal cancer. Virchows Arch. 470, 37-45. doi: $10.1007 / \mathrm{s} 00428-016-2037-3$

Hentze, M. W., Castello, A., Schwarzl, T., and Preiss, T. (2018). A brave new world of RNA-binding proteins. Nat. Rev. Mol. Cell Biol. 19, 327-341. doi: 10.1038/nrm.2017.130

Hope, N. R., and Murray, G. I. (2011). The expression profile of RNAbinding proteins in primary and metastatic colorectal cancer: relationship of heterogeneous nuclear ribonucleoproteins with prognosis. Hum. Pathol. 42, 393-402. doi: 10.1016/j.humpath.2010.08.006

Iadevaia, V., and Gerber, A. P. (2015). Combinatorial control of mRNA fates by RNA-binding proteins and non-coding RNAs. Biomolecules 5, 2207-2222. doi: 10.3390/biom5042207

Ingolia, N. T., Ghaemmaghami, S., Newman, J. R. S., and Weissman, J. S. (2009). Genome-wide analysis in vivo of translation with nucleotide resolution using ribosome profiling. Science 324, 218-223. doi: 10.1126/science.1168978

Iwata, N., Ishikawa, T., Okazaki, S., Mogushi, K., Baba, H., Ishiguro, M., et al. (2017). Clinical significance of methylation and reduced expression of the quaking gene in colorectal cancer. Anticancer Res. 37, 489-498. doi: 10.21873/anticanres.11341

Jang, H. H., Lee, H. N., Kim, S. Y., Hong, S., and Lee, W. S. (2017). Expression of RNA-binding motif protein 3 (RBM3) and cold-inducible RNA-binding protein (CIRP) is associated with improved clinical outcome in patients with colon cancer. Anticancer Res. 37, 1779-1785. doi: 10.21873/anticanres.11511

Ji, S., Ye, G., Zhang, J., Wang, L., Wang, T., Wang, Z., et al. (2013). miR-574-5p negatively regulates Qki6/7 to impact b-catenin/Wnt signalling and the development of colorectal cancer. Gut 62, 716-726. doi: 10.1136/gutjnl-2011-301083

Jiang, Q., Crews, L. A., Holm, F., and Jamieson, C. H. M. (2017). RNA editingdependent epitranscriptome diversity in cancer stem cells. Nat. Rev. Cancer 17, 381-392. doi: 10.1038/nrc.2017.23

Jiang, S., and Baltimore, D. (2016). RNA-binding protein Lin28 in cancer and immunity. Cancer Lett. 375, 108-113. doi: 10.1016/j.canlet.2016.02.050

Jin, Z., Liang, F., Yang, J., and Mei, W. (2017). hnRNP I regulates neonatal immune adaptation and prevents colitis and colorectal cancer. PLoS Genet. 13:1006672. doi: 10.1371/journal.pgen.1006672

Jones, P., Binns, D., Chang, H. Y., Fraser, M., Li, W., Mcanulla, C., et al. (2014). InterProScan 5: genome-scale protein function classification. Bioinformatics 30, 1236-1240. doi: 10.1093/bioinformatics/btu031

Kechavarzi, B., and Janga, S. C. (2014). Dissecting the expression landscape of RNA-binding proteins in human cancers. Genome Biol. 15:R14. doi: 10.1186/gb-2014-15-1-r14

Keene, J. D. (2007). RNA regulons: coordination of post-transcriptional events. Nat. Rev. Genet. 8, 533-543. doi: 10.1038/nrg2111

Kharas, M. G., and Lengner, C. J. (2017). Stem cells, cancer, and MUSASHI in blood and guts. Trends Cancer 3, 347-356. doi: 10.1016/j.trecan.2017.03.007

Kim, H. H., and Gorospe, M. (2008). GU-Rich RNA: expanding CUGBP1 function, broadening mRNA turnover. Mol. Cell 29, 151-152. doi: 10.1016/j.molcel.2008.01.005

Kim, S. K., Lee, H., Han, K., Kim, S. C., Choi, Y., Park, S. W., et al. (2014). SET7/9 methylation of the pluripotency factor LIN28A is a nucleolar localization mechanism that blocks let-7 biogenesis in human ESCs. Cell Stem Cell 15, 735-749. doi: 10.1016/j.stem.2014.10.016

King, C. E., Cuatrecasas, M., Castells, A., Sepulveda, A. R., Lee, J. S., and Rustgi, A. K. (2011a). Tumor and stem cell biology LIN28B promotes colon cancer progression and metastasis. Cancer Res. 71, 4260-4268. doi: 10.1158/0008-5472.CAN-10-4637

King, C. E., Wang, L., Winograd, R., Madison, B. B., Mongroo, P. S., Johnstone, C. N., et al. (2011b). LIN28B fosters colon cancer migration, invasion and transformation through let-7-dependent and -independent mechanisms. Oncogene 30, 4185-4193. doi: 10.1038/onc.2011.131

Kondo, T., Furuta, T., Mitsunaga, K., Ebersole, T. A., Shichiri, M., Wu, J., et al. (1999). Genomic organization and expression analysis of the mouse qkI locus. Mamm. Genome 10, 662-669.

Kumara, H. S., Kirchoff, D., Caballero, O. L., Su, T., Ahmed, A., Herath, S. A., et al. (2015). Expression of the cancer testis antigen IGF2BP3 in colorectal cancers; 
IGF2BP3 holds promise as a specific immunotherapy target. Oncoscience 2, 607-614. doi: 10.18632/oncoscience.174

Lai, C. H., Huang, Y. C., Lee, J. C., Ta-Chien Tseng, J., Chang, K. C., Chen, Y. J., et al. (2016). Translational upregulation of Aurora-A by hnRNP Q1 contributes to cell proliferation and tumorigenesis in colorectal cancer. Cell Death Dis. 8:e2555. doi: 10.1038/cddis.2016.479

Lai, W. S., Carballo, E., Strum, J. R., Kennington, E. A., Phillips, R. S., and Blackshear, P. J. (1999). Evidence that tristetraprolin binds to AU-rich elements and promotes the deadenylation and destabilization of tumor necrosis factor alpha mRNA. Mol. Cell. Biol. 19, 4311-4323. doi: 10.1128/MCB.19.6.4311

Lan, L., Appelman, C., Smith, A. R., Yu, J., Larsen, S., Marquez, R. T., et al. (2015). Natural product (-)-gossypol inhibits colon cancer cell growth by targeting RNA-binding protein Musashi-1. Mol. Oncol. 9, 1406-1420. doi: 10.1016/j.molonc.2015.03.014

Lederer, M., Bley, N., Schleifer, C., and Hüttelmaier, S. (2014). The role of the oncofetal IGF2 mRNA-binding protein 3 (IGF2BP3) in cancer. Semin. Cancer Biol. 29, 3-12. doi: 10.1016/j.semcancer.2014.07.006

Lee, H. H., Son, Y. J., Lee, W. H., Park, Y. W., Chae, S. W., Cho, W. J., et al. (2010). Tristetraprolin regulates expression of VEGF and tumorigenesis in human colon cancer. Int. J. Cancer 126, 1817-1827. doi: 10.1002/ijc.24847

Lee, H. H., Yang, S. S., Vo, M. T., Cho, W. J., Lee, B. J., Leem, S. H., et al. (2013). Tristetraprolin down-regulates IL-23 expression in colon cancer cells. Mol. Cells 36, 571-576. doi: 10.1007/s10059-013-0268-6

Lee, S. R., Jin, H., Kim, W. T., Kim, W. J., Kim, S. Z., Leem, S. H., et al. (2018). Tristetraprolin activation by resveratrol inhibits the proliferation and metastasis of colorectal cancer cells. Int. J. Oncol. 53, 1269-1278. doi: $10.3892 /$ ijo.2018.4453

Leontieva, O. V., and Ionov, Y. (2009). RNA-binding motif protein 35A is a novel tumor suppressor for colorectal cancer. Cell Cycle 8, 490-497. doi: $10.4161 /$ cc.8.3.7679

Li, D., Peng, X., Yan, D., Tang, H., Huang, F., Yang, Y., et al. (2011). Msi-1 is a predictor of survival and a novel therapeutic target in colon cancer. Ann. Surg. Oncol. 18, 2074-2083. doi: 10.1245/s10434-011-1567-9

Li, D., Yan, D., Tang, H., Zhou, C., Fan, J., Li, S., et al. (2009). IMP3 Is a novel prognostic marker that correlates with colon cancer progression and pathogenesis. Ann. Surg. Oncol. 16, 3499-3506. doi: 10.1245/s10434-009-0648-5

Li, L., Yu, C., Gao, H., and Li, Y. (2010). Argonaute proteins: potential biomarkers for human colon cancer. BMC Cancer 10:38. doi: 10.1186/1471-24 07-10-38

Liang, L., Li, X., Zhang, X., Lv, Z., He, G., Zhao, W., et al. (2013). MicroRNA-137, an HMGA1 target, suppresses colorectal cancer cell invasion and metastasis in mice by directly targeting FMNL2. Gastroenterology 144, 624-635.e4. doi: 10.1053/j.gastro.2012.11.033

Liao, W. T., Liu, J. L., Wang, Z. G., Cui, Y. M., Shi, L., Li, T. T., et al. (2013). High expression level and nuclear localization of Sam68 are associated with progression and poor prognosis in colorectal cancer. BMC Gastroenterol. 13:126. doi: 10.1186/1471-230X-13-126

Lichtner, P., Attié-Bitach, T., Schuffenhauer, S., Henwood, J., Bouvagnet, P., Scambler, P., et al. (2002). Expression and mutation analysis of BRUNOL3, a candidate gene for heart and thymus developmental defects associated with partial monosomy 10p. J. Mol. Med. 80, 431-442. doi: 10.1007/s00109-002-0331-9

Lin, G. L., Ting, H. J., Tseng, T. C., Juang, V., and Lo, Y. L. (2017). Modulation of the mRNA-binding protein $\mathrm{HuR}$ as a novel reversal mechanism of epirubicin-triggered multidrug resistance in colorectal cancer cells. PLOS ONE 12:e0185625. doi: 10.1371/journal.pone.0185625

Lin, L., Zhang, J., Wang, Y., Ju, W., Ma, Y., Li, L., et al. (2013). Insulinlike growth factor-II mRNA-binding protein 3 predicts a poor prognosis for colorectal adenocarcinoma. Oncol. Lett. 6, 740-744. doi: 10.3892/ol.2013. 1458

Liu, L., Christodoulou-Vafeiadou, E., Rao, J. N., Zou, T., Xiao, L., Kyoung Chung, H., et al. (2014). RNA-binding protein HuR promotes growth of small intestinal mucosa by activating the Wnt signaling pathway. Mol. Biol. Cell 25, 3308-3318. doi: 10.1091/mbc.e14-03-0853

Liu, L., Ouyang, M., Rao, J. N., Zou, T., Xiao, L., Chung, H. K., et al. (2015). Competition between RNA-binding proteins CELF1 and HuR modulates MYC translation and intestinal epithelium renewal. Mol. Biol. Cell 26, 1797-1810. doi: 10.1091/mbc.E14-11-1500

Liu, Q., Luo, Y., Li, X., Yuan, L., Xu, R., and Yang, J. Y. (2013). Preparation and characterizations of polyclonal antibodies against STAR protein QKI7b. Appl. Biochem. Biotechnol. 169, 2273-2280. doi: 10.1007/s12010-012-0081-2

Liu, W., Li, Z., Xu, W., Wang, Q., and Yang, S. (2013). Humoral autoimmune response to IGF2 mRNA-binding protein (IMP2/p62) and its tissuespecific expression in colon cancer. Scand. J. Immunol. 77, 255-260. doi: $10.1111 /$ sji.12032

Liu, Y., Chen, X., Cheng, R., Yang, F., Yu, M., Wang, C., et al. (2018). The Jun/miR$22 / \mathrm{HuR}$ regulatory axis contributes to tumourigenesis in colorectal cancer. Mol. Cancer 17:11. doi: 10.1186/s12943-017-0751-3

Liu, Y., Liu, R., Yang, F., Cheng, R., Chen, X., Cui, S., et al. (2017). miR-19a promotes colorectal cancer proliferation and migration by targeting TIA1. Mol. Cancer 16:53. doi: 10.1186/s12943-017-0625-8

Liu, Z. P., Liu, S., Chen, R., Huang, X., and Wu, L. Y. (2017). Structure alignment-based classification of RNA-binding pockets reveals regional RNA recognition motifs on protein surfaces. BMC Bioinformatics 18:27. doi: 10.1186/s12859-016-1410-1

Lochhead, P., Imamura, Y., Morikawa, T., Kuchiba, A., Yamauchi, M., Liao, X., et al. (2012). Insulin-like growth factor 2 messenger RNA binding protein 3 (IGF2BP3) is a marker of unfavourable prognosis in colorectal cancer. Eur. J. Cancer 48, 3405-3413. doi: 10.1016/j.ejca.2012.06.021

López de Silanes, I., Fan, J., Galbán, C. J., Spencer, R. G., Becker, K. G., and Gorospe, M. (2004a). Global analysis of HuR-regulated gene expression in colon cancer systems of reducing complexity. Gene Expr. 12, 49-59. doi: 10.3727/000000004783992215

López de Silanes, I., Fan, J., Yang, X., Zonderman, A. B., Potapova, O., Pizer, E. S., et al. (2003). Role of the RNA-binding protein HuR in colon carcinogenesis. Oncogene 22, 7146-7154. doi: 10.1038/sj.onc.1206862

López de Silanes, I., Lal, A., and Gorospe, M. (2011). HuR: post-transcriptional paths to malignancy. RNA Biol. 2, 11-13. doi: 10.4161/rna.2.1.1552

López de Silanes, I., Zhan, M., Lal, A., Yang, X., and Gorospe, M. (2004b). Identification of a target RNA motif for RNA-binding protein HuR. Proc. Natl. Acad. Sci. U.S.A. 101, 2987-2992. doi: 10.1073/pnas.0306453101

López-Cortés, A., Paz-y-Miño, C., Guerrero, S., Jaramillo-Koupermann, G., Intriago-Baldéon, D., García, J., et al. (2019). Pharmacogenomics, biomarker network and allele frequencies in colorectal cancer. bioRxiv [preprint]. bioRxiv:561316. doi: 10.1101/561316

Lukong, K. E., Chang, K. W., Khandjian, E. W., and Phane Richard, S. (2008). RNA-binding proteins in human genetic disease. Cell 24, 416-425. doi: 10.1016/j.tig.2008.05.004

Lukong, K. E., and Richard, S. (2007). Targeting the RNA-binding protein Sam68 as a treatment for cancer? Futur. Oncol. 3, 539-544. doi: 10.2217/14796694.3.5.539

Madison, B. B., Jeganathan, A. N., Mizuno, R., Winslow, M. M., Castells, A., Cuatrecasas, M., et al. (2015). Let-7 represses carcinogenesis and a stem cell phenotype in the intestine via regulation of hmga2. PLoS Genet. 11:e1005408. doi: 10.1371/journal.pgen.1005408

Madison, B. B., Liu, Q., Zhong, X., Hahn, C. M., Lin, N., Emmett, M. J., et al. (2013). LIN28B promotes growth and tumorigenesis of the intestinal epithelium via Let-7. Genes Dev. 27, 2233-2245. doi: 10.1101/gad.224659.113

Mager, L. F., Koelzer, V. H., Stuber, R., Thoo, L., Keller, I., Koeck, I., et al. (2017). The ESRP1-GPR137 axis contributes to intestinal pathogenesis. Elife 6:e28366. doi: 10.7554/eLife.28366

Martinez-Useros, J., Garcia-Carbonero, N., Li, W., Fernandez-Aceñero, M. J., Cristobal, I., Rincon, R., et al. (2019). UNR/CSDE1 expression is critical to maintain invasive phenotype of colorectal cancer through regulation of c-MYC and epithelial-to-mesenchymal transition. J. Clin. Med. 8:560. doi: $10.3390 / \mathrm{jcm} 8040560$

Martinez-Useros, J., Georgiev-Hristov, T., Fernández-Aceñero, M. J., BorreroPalacios, A., Indacochea, A., Guerrero, S., et al. (2017). UNR/CDSE1 expression as prognosis biomarker in resectable pancreatic ductal adenocarcinoma patients: a proof-of-concept. PLoS ONE 12:e0182044. doi: 10.1371/journal.pone.0182044

Mayr, C., Hemann, M. T., and Bartel, D. P. (2007). Disrupting the pairing between let-7 and Hmga2 enhances oncogenic transformation. Science 315, 1576-1579. doi: $10.1126 /$ science.1137999 
Melling, N., Simon, R., Mirlacher, M., Izbicki, J. R., Stahl, P., Terracciano, L. M., et al. (2016). Loss of RNA-binding motif protein 3 expression is associated with right-sided localization and poor prognosis in colorectal cancer. Histopathology 68, 191-198. doi: 10.1111/his.12726

Morris, A. R., Bos, A., Diosdado, B., Agami, R., Meijer, G. A., Carvalho, B., et al. (2012). Alternative cleavage and polyadenylation during colorectal cancer development. Clin. Cancer Res. 18, 5256-5266. doi: 10.1158/1078-0432.CCR-12-0543

Natarajan, G., Ramalingam, S., Ramachandran, I., May, R., Queimado, L., Houchen, C. W., et al. (2008). CUGBP2 downregulation by prostaglandin E 2 protects colon cancer cells from radiation-induced mitotic catastrophe. Am. J. Physiol. Gastrointest. Liver Physiol. 294, 1235-1244. doi: 10.1152/ajpgi.00037.2008

Negrini, S., Gorgoulis, V. G., and Halazonetis, T. D. (2010). Genomic instability - an evolving hallmark of cancer. Nat. Rev. Mol. Cell Biol. 11, 220-228. doi: $10.1038 / \mathrm{nrm} 2858$

Nilsen, T. W., and Graveley, B. R. (2010). Expansion of the eukaryotic proteome by alternative splicing. Nature 463, 457-463. doi: 10.1038/nature08909

Okano, H., Kawahara, H., Toriya, M., Nakao, K., Shibata, S., and Imai, T. (2005). Function of RNA-binding protein Musashi-1 in stem cells. Exp. Cell Res. 306, 349-356. doi: 10.1016/j.yexcr.2005.02.021

Olive, V., Bennett, M. J., Walker, J. C., Ma, C., Jiang, I., Cordon-Cardo, C., et al. (2009). miR-19 is a key oncogenic component of mir-17-92. Genes Dev. 23, 2839-2849. doi: 10.1101/gad.1861409

Pang, M., Wu, G., Hou, X., Hou, N., Liang, L., Jia, G., et al. (2014). LIN28B promotes colon cancer migration and recurrence. PLOS ONE 9:e109169. doi: 10.1371/journal.pone.0109169

Paz-Y-Mino, C., Salazar, C. A., López-Cortés, A., and Leone, P. E. (2015). Positive association between the polymorphic variant CCND1 A870G and colorectal cancer in Ecuadorian mestizo population. J. Can. Res. Updates 4, 163-170. doi: 10.6000/1929-2279.2015.04.04.4

Pereira, B., Billaud, M., and Almeida, R. (2017). RNA-binding proteins in cancer: old players and new actors. Trends Cancer 3, 506-528. doi: 10.1016/j.trecan.2017.05.003

Piskounova, E., Polytarchou, C., Thornton, J. E., Lapierre, R. J., Pothoulakis, C., Hagan, J. P., et al. (2011). Lin28A and Lin28B inhibit let-7 microRNA biogenesis by distinct mechanisms. Cell 147, 1066-1079. doi: 10.1016/j.cell.2011.10.039

Piskounova, E., Viswanathan, S. R., Janas, M., LaPierre, R. J., Daley, G. Q., Sliz, P., et al. (2008). Determinants of microRNA processing inhibition by the developmentally regulated RNA-binding protein Lin28. J. Biol. Chem. 283, 21310-21314. doi: 10.1074/jbc.C800108200

Pontén, F., Jirström, K., and Uhlen, M. (2008). The human protein atlas-a tool for pathology. J. Pathol. 216, 387-393. doi: 10.1002/path.2440

Potten, C. S., Booth, C., Tudor, G. L., Booth, D., Brady, G., Hurley, P., et al. (2003). Identification of a putative intestinal stem cell and early lineage marker; musashi-1. Differentiation 71, 28-41. doi: 10.1046/j.1432-0436.2003.700603.x

Qiao, L., and Wong, B. C. Y. (2009). Role of notch signaling in colorectal cancer. Carcinogenesis 30, 1979-1986. doi: 10.1093/carcin/bgp236

Ramalingam, S., Natarajan, G., Schafer, C., Subramaniam, D., May, R., Ramachandran, I., et al. (2008). Novel intestinal splice variants of RNAbinding protein CUGBP2: isoform-specific effects on mitotic catastrophe HHS public access. Am. J. Physiol. Gastrointest. Liver Physiol. 294, 971-981. doi: 10.1152/ajpgi.00540.2007

Ramalingam, S., Ramamoorthy, P., Subramaniam, D., and Anant, S. (2012). Reduced expression of RNA binding protein CELF2, a putative tumor suppressor gene in colon cancer. Immunogastroenterology 1, 27-33. doi: $10.7178 /$ ig.1.1.7

Rappaport, N., Fishilevich, S., Nudel, R., Twik, M., Belinky, F., Plaschkes, I., et al. (2017). Rational confederation of genes and diseases: NGS interpretation via GeneCards, MalaCards and VarElect. Biomed. Eng. Online 16(Suppl. 1):72. doi: 10.1186/s12938-017-0359-2

Ross, J., Lemm, I., and Berberet, B. (2001). Overexpression of an mRNAbinding protein in human colorectal cancer. Oncogene 20, 6544-6550. doi: 10.1038/sj.onc. 1204838

Rüdel, S., Wang, Y., Lenobel, R., Körner, R., Hsiao, H. H., Urlaub, H., et al. (2011). Phosphorylation of human argonaute proteins affects small RNA binding. Nucleic Acids Res. 39, 2330-2343. doi: 10.1093/nar/gkq1032
Sakakibara, S., Nakamura, Y., Satoh, H., and Okano, H. (2001). Rna-binding protein Musashi2: developmentally regulated expression in neural precursor cells and subpopulations of neurons in mammalian CNS. J. Neurosci. 21, 8091-8107. doi: 10.1523/JNEUROSCI.21-20-08091.2001

Sakurai, T., Kashida, H., Watanabe, T., Hagiwara, S., Mizushima, T., Iijima, H., et al. (2014). Stress response protein cirp links inflammation and tumorigenesis in colitis-associated cancer. Cancer Res. 74, 6119-6128. doi: 10.1158/0008-5472.CAN-14-0471

Sánchez-Jiménez, F., and Sánchez-Margalet, V. (2013). Role of Sam68 in post-transcriptional gene regulation. Int. J. Mol. Sci. 14, 23402-23419. doi: 10.3390/ijms141223402

Sharma, A., Bhat, A. A., Krishnan, M., Singh, A. B., and Dhawan, P. (2013). Trichostatin-A modulates claudin-1 mRNA stability through the modulation of hu antigen $\mathrm{R}$ and tristetraprolin in colon cancer cells. Carcinogenesis 34, 2610-2621. doi: 10.1093/carcin/bgt207

Siesing, C., Sorbye, H., Dragomir, A., Qvortrup, C., Pontén, F., Jirströ, K., et al. (2017). High RBM3 expression is associated with an improved survival and oxaliplatin response in patients with metastatic colorectal cancer. PLoS ONE 12:e0182512. doi: 10.1371/journal.pone.0182512

Smith, A. R. (2015). The Regulation of Musashi RNA Binding Proteins and the Implications for Cancer Therapy (Ph.D. Dissertation). University of Kansas.

Smith, A. R., Marquez, R. T., Tsao, W. C., Pathak, S., Roy, A., Ping, J., et al. (2015). Tumor suppressive microRNA-137 negatively regulates Musashi-1 and colorectal cancer progression. Oncotarget 6, 12558-12573. doi: 10.18632/oncotarget.3726

Sobolewski, C., Sanduja, S., Blanco, F. F., Hu, L., and Dixon, D. A. (2015). Histone deacetylase inhibitors activate tristetraprolin expression through induction of early growth response protein 1 (EGR1) in colorectal cancer cells. Biomolecules 5, 2035-2055. doi: 10.3390/biom5032035

Sugimasa, H., Taniue, K., Kurimoto, A., Takeda, Y., Kawasaki, Y., and Akiyama, T. (2015). Heterogeneous nuclear ribonucleoprotein $\mathrm{K}$ upregulates the kinetochore complex component NUF2 and promotes the tumorigenicity of colon cancer cells. Biochem. Biophys. Res. Commun. 459, 29-35. doi: 10.1016/j.bbrc.2015.02.043

Sureban, S. M., Ramalingam, S., Natarajan, G., May, R., Subramaniam, D., Bishnupuri, K. S., et al. (2008). Translation regulatory factor RBM3 is a proto-oncogene that prevents mitotic catastrophe. Oncogene 27, 4544-4556. doi: 10.1038/onc.2008.97

Szklarczyk, D., Morris, J. H., Cook, H., Kuhn, M., Wyder, S., Simonovic, M., et al. (2017). The STRING database in 2017: quality-controlled proteinprotein association networks, made broadly accessible. Nucleic Acids Res. 45, D362-D368. doi: 10.1093/nar/gkw937

The UniProt Consortium (2019). UniProt: a worldwide hub of protein knowledge. Nucleic Acids Res. 47, D506-D515. doi: 10.1093/nar/gky1049

Todaro, M., Gaggianesi, M., Catalano, V., Benfante, A., Iovino, F., Biffoni, M., et al. (2014). Cell stem cell article CD44v6 is a marker of constitutive and reprogrammed cancer stem cells driving colon cancer metastasis. Stem Cell 14, 342-356. doi: 10.1016/j.stem.2014.01.009

Tomczak, K., Czerwinska, P., and Wiznerowicz, M. (2015). The cancer genome atlas (TCGA): an immeasurable source of knowledge. Contemp. Oncol. 19, 68-77. doi: 10.5114/wo.2014.47136

Triboulet, R., Pirouz, M., and Gregory, R. I. (2015). A single Let-7 microRNA bypasses LIN28-mediated repression. Cell Rep. 13, 260-266. doi: 10.1016/j.celrep.2015.08.086

Tu, H. C., Schwitalla, S., Qian, Z., LaPier, G. S., Yermalovich, A., Ku, Y. C., et al. (2015). LIN28 cooperates with WNT signaling to drive invasive intestinal and colorectal adenocarcinoma in mice and humans. Genes Dev. 29, 1074-1086. doi: $10.1101 /$ gad.256693.114

Ushigome, M., Ubagai, T., Fukuda, H., Tsuchiya, N., Sugimura, T., Takatsuka, J., et al. (2005). Up-regulation of hnRNP Al gene in sporadic human colorectal cancers. Int. J. Oncol. 26, 635-640. doi: 10.3892/ijo.26.3.635

Vainer, G., Vainer-Mosse, E., Pikarsky, A., Shenoy, S., Oberman, F., Yeffet, A., et al. (2008). A role for VICKZ proteins in the progression of colorectal carcinomas: regulating lamellipodia formation. J. Pathol. 215, 445-456. doi: $10.1002 /$ path.2376

Venugopal, A., Subramaniam, D., Balmaceda, J., Roy, B., Dixon, D. A., Umar, S., et al. (2016). RNA binding protein RBM3 increases b-catenin signaling to 
increase stem cell characteristics in colorectal cancer cells. Mol. Carcinog. 55, 1503-1516. doi: 10.1002/mc.22404

Viswanathan, S. R., and Daley, G. Q. (2010). Lin28: a microRNA regulator with a macro role. Cell 140, 445-449. doi: 10.1016/j.cell.2010.02.007

Viswanathan, S. R., Powers, J. T., Einhorn, W., Hoshida, Y., Ng, T. L., Toffanin, S., et al. (2009). Lin28 promotes transformation and is associated with advanced human malignancies. Nat. Genet. 41, 843-848. doi: 10.1038/ ng.392

Vlasova, I. A., Tahoe, N. M., Fan, D., Larsson, O., Rattenbacher, B., SternJohn, J. R., et al. (2008). Conserved GU-rich elements mediate mRNA decay by binding to CUG-binding protein 1. Mol. Cell 29, 263-270. doi: 10.1016/j.molcel.2007.11.024

Vlasova-St. Louis, I., and Bohjanen, P. R. (2011). Coordinate regulation of mRNA decay networks by GU-rich elements and CELF1. Curr. Opin. Genet. Dev. 21, 444-451. doi: 10.1016/j.gde.2011.03.002

Voutsadakis, I. A. (2018). The pluripotency network in colorectal cancer pathogenesis and prognosis: an update. Biomark. Med. 12, 653-665. doi: 10.2217/bmm-2017-0369

Wang, M. J., Ping, J., Li, Y., Adell, G., Arbman, G., Nodin, B., et al. (2015). The prognostic factors and multiple biomarkers in young patients with colorectal cancer. Sci. Rep. 5:10645. doi: 10.1038/srep 10645

Wang, S., Li, N., Yousefi, M., Nakauka-Ddamba, A., Li, F., Parada, K., et al. (2015). Transformation of the intestinal epithelium by the MSI2 RNA-binding protein. Nat. Commun. 6:6517. doi: 10.1038/ncomms7517

Wang, T., He, Y., Zhu, Y., Chen, M., Weng, M., Yang, C., et al. (2016). Comparison of the expression and function of Lin28A and Lin28B in colon cancer. Oncotarget 7, 79605-796116. doi: 10.18632/oncotarget.12869

Wang, T., Wang, G., Hao, D., Liu, X., Wang, D., Ning, N., et al. (2015). Aberrant regulation of the LIN28A/LIN28B and let-7 loop in human malignant tumors and its effects on the hallmarks of cancer. Mol. Cancer 14, 1-13. doi: 10.1186/s12943-015-0402-5

Wei, Q., Huang, X., Fu, B., Liu, J., Zhong, L., Yang, Q., et al. (2015). IMP3 expression in biopsy specimens of colorectal cancer predicts lymph node metastasis and TNM stage. Int. J. Clin. Exp. Pathol. 8, 11024-11032.

Wurth, L. (2012). Versatility of RNA-binding proteins in cancer. Comp. Funct. Genomics 2012, 1-11. doi: 10.1155/2012/178525

Wurth, L., and Gebauer, F. (2015). RNA-binding proteins, multifaceted translational regulators in cancer. Biochim. Biophys. Acta 1849, 881-886. doi: 10.1016/j.bbagrm.2014.10.001

Wurth, L., Papasaikas, P., Olmeda, D., Bley, N., Calvo, G. T., Guerrero, S., et al. (2016). UNR/CSDE1 drives a post-transcriptional program to promote melanoma invasion and metastasis. Cancer Cell 30, 694-707. doi: 10.1016/j.ccell.2016.10.004

Yang, G., Fu, H., Zhang, J., Lu, X., Yu, F., Jin, L., et al. (2010). RNAbinding protein quaking, a critical regulator of colon epithelial differentiation and a suppressor of colon cancer. Gastroenterology 138, 231-240.e5. doi: 10.1053/j.gastro.2009.08.001

Yang, H., Rao, J. N., and Wang, J. Y. (2014). Posttranscriptional regulation of intestinal epithelial tight junction barrier by RNA-binding proteins and microRNAs. Tissue Barriers 2:e28320. doi: 10.4161/tisb.28320

Ye, F., Jin, P., Cai, X., Cai, P., and Cai, H. (2017). High RNA-binding motif protein 3 (RBM3) expression is independently associated with prolonged overall survival in intestinal-type gastric cancer. Med. Sci. Monit. 23, 6033-6041. doi: 10.12659/MSM.905314
Ye, S., Song, W., Xu, X., Zhao, X., and Yang, L. (2016). IGF2BP2 promotes colorectal cancer cell proliferation and survival through interfering with RAF-1 degradation by miR-195. FEBS Lett. 590, 1641-1650. doi: 10.1002/1873-3468.12205

Yiakouvaki, A., Dimitriou, M., Karakasiliotis, I., Eftychi, C., Theocharis, S., and Kontoyiannis, D. L. (2012). Myeloid cell expression of the RNA-binding protein HuR protects mice from pathologic inflammation and colorectal carcinogenesis. J. Clin. Invest. 122, 48-61. doi: 10.1172/JCI45021

Yu, C., Mannan, A. M., Yvone, G. M., Ross, K. N., Zhang, Y. L., Marton, M. A., et al. (2016). High-throughput identification of genotype-specific cancer vulnerabilities in mixtures of barcoded tumor cell lines. Nat. Biotechnol. 34, 419-423. doi: 10.1038/nbt.3460

Yuqi, L., Chengtang, W., Ying, W., Shangtong, L., and Kangxiong, L. (2008). The expression of Msi-1 and its significance in small intestinal mucosa severely damaged by high-dose 5-FU. Dig. Dis. Sci. 53, 2436-2442. doi: 10.1007/s10620-007-0155-0

Zhang, H., Zong, Y., Qiu, G., Jia, R., Xu, X., Wang, F., et al. (2018). Silencing Lin28 promotes apoptosis in colorectal cancer cells by upregulating let7c targeting of antiapoptotic BCL2L1. Mol. Med. Rep. 17, 5143-5149. doi: 10.3892/mmr.2018.8483

Zhang, Q. S., Manche, L., Xu, R. M., and Krainer, A. R. (2006). hnRNP Al associates with telomere ends and stimulates telomerase activity. RNA 12, 1116-1128. doi: 10.1261/rna.58806

Zhang, Z., Zhou, C., Chang, Y., Zhang, Z., Hu, Y., Zhang, F., et al. (2016). Long non-coding RNA CASC11 interacts with hnRNP-K and activates the WNT/ $\beta$ catenin pathway to promote growth and metastasis in colorectal cancer. Cancer Lett. 376, 62-73. doi: 10.1016/j.canlet.2016.03.022

Zhong, X., Xiao, Y., Chen, C., Wei, X., Hu, C., Ling, X., et al. (2015). MicroRNA203-mediated posttranscriptional deregulation of CPEB4 contributes to colorectal cancer progression. Biochem. Biophys. Res. Commun. 466, 206-213. doi: 10.1016/j.bbrc.2015.09.008

Zhou, J., Ng, S. B., and Chng, W. J. (2013). LIN28/LIN28B: an emerging oncogenic driver in cancer stem cells. Int. J. Biochem. Cell Biol. 45, 973-978. doi: 10.1016/j.biocel.2013.02.006

Zlobec, I., Karamitopoulou, E., Terracciano, L., Piscuoglio, S., Iezzi, G., Muraro, G., et al. (2010). TIA-1 cytotoxic granule-associated RNA binding protein improves the prognostic performance of CD8 in mismatch repair-proficient colorectal cancer. PLoS ONE 5:e14282. doi: 10.1371/journal.pone.0014282

Zucconi, B. E., and Wilson, G. M. (2011). Modulation of neoplastic gene regulatory pathways by the RNA-binding factor AUF1. Front. Biosci. 16, 2307-2325. doi: $10.2741 / 3855$

Conflict of Interest Statement: The authors declare that the research was conducted in the absence of any commercial or financial relationships that could be construed as a potential conflict of interest.

Copyright (C) 2019 García-Cárdenas, Guerrero, López-Cortés, Armendáriz-Castillo, Guevara-Ramírez, Pérez-Villa, Yumiceba, Zambrano, Leone and Paz-y-Miño. This is an open-access article distributed under the terms of the Creative Commons Attribution License (CC BY). The use, distribution or reproduction in other forums is permitted, provided the original author(s) and the copyright owner(s) are credited and that the original publication in this journal is cited, in accordance with accepted academic practice. No use, distribution or reproduction is permitted which does not comply with these terms. 